\title{
Impact of technology uncertainty on future low-carbon pathways in the UK
}

\author{
Birgit Fais ${ }^{1}$, Ilkka Keppo, Marianne Zeyringer, Will Usher, Hannah Daly \\ UCL Energy Institute, University College London
}

\begin{abstract}
Energy and climate policy-making requires strong quantitative scientific evidence to devise robust and consistent long-term decarbonisation strategies. Energy system modelling can provide crucial insights into the inherent uncertainty in such strategies, which needs to be understood when designing appropriate policy measures.

This study contributes to the growing research area of uncertainty analysis in energy system models. We combine consistent and realistic narratives on several technology dimensions with a global sensitivity analysis in a national, bottom-up, optimizing energy system model. This produces structured insights into the impact of low-carbon technology and resource availability on the long-term development of the UK energy system under ambitious decarbonisation pathways. We explore a variety of result metrics to present policy-relevant results in a useful and concise manner. The results provide valuable information on the variability of fuel and technology use across the uncertainty space (e.g. a strong variation in natural gas demand). We demonstrate the complementarities and substitutability of technologies (e.g. the dependency of hydrogen technologies on the availability of CCS). We highlight critical low-carbon options and hedging strategies (e.g. the early decarbonisation of the electricity sector or the stronger use of renewable sources as a hedging against failure in other technologies) and demonstrate timing and path dependencies (e.g. the importance of early decarbonisation action in the presence of multiple technology uncertainty). The results also show how the availability of a given technology can have wider impacts elsewhere in the energy system, thus complicating the management of a long-term energy transition.
\end{abstract}

Keywords: Energy systems analysis; sensitivity analysis; uncertainty; emission reduction; low-carbon technologies;

\section{Introduction}

Quantitative energy modelling currently plays a fundamental role in informing decision-making in energy and climate policies on efficient long-term decarbonisation strategies, both on a global (IEA, 2015a) and national level (Ekins et al., 2011). Given the uncertainty and complexity of future lowcarbon pathways, these energy-economic studies usually present their results as a small set of qualitatively different scenarios which can be described as "plausible, challenging and relevant stories about how the future might unfold" (Raskin et al., 2005).

In brief, the modelling/policy process works as follows. Decision makers rely upon policy reports for objective and balanced information. The development of a policy report is supported by the results of a modelling exercise. And these reports are used to help set long-term target levels for emission reduction, energy efficiency or use of renewable energies and outline the major technology strategies to fulfil these objectives. But particularly when analysing national policy reports, it becomes obvious that they usually rely on a small set of scenarios (e.g. DECC, 2011a; EWI et al., 2010) derived from deterministic energy system models. While acknowledging the need to deliver clear and concise messages to policy makers,

1 Corresponding author: Birgit Fais, email: b.fais@ucl.ac.uk 
it is apparent that such analyses are limited in terms of their description of uncertainty in the projected decarbonisation pathways they report. This may lead to an overreliance on certain technologies or mitigation strategies which feature strongly in the presented scenarios (availability bias).

While climate analysis has already progressed considerably in terms of uncertainty analysis (cf. for example IPCC (2014)), it still seems to be an emerging technique in energy systems studies. Different approaches to represent uncertainty in energy-economic models can be observed in literature. The most common methods are Sensitivity Analyses evaluating the variability of the model output as a function of changing input parameters in deterministic models (Saltelli et al., 2010). In order to further include interactions between input parameters, Global Sensitivity Techniques, which vary several uncertain input parameters at a time to explore the interaction effects, in some cases through probabilistic and Monte Carlo methods, have been developed (Wainwright et al., 2014). Recent studies with global sensitivity approaches in energy systems research are van Vuuren et al. (2008), Anthoff \& Tol (2013), Anderson et al. (2014), Branger et al. (2015), Pye et al. (2015) and Usher (2016). Other methods include Stochastic Modelling (Krey et al., 2007; Keppo \& van der Zwaan, 2012, Usher \& Strachan, 2012; Labriet et al., 2012; Syri et al., 2008; Kanudia \& Loulou, 1998; Seljom \& Tomasgarda, 2015), Modelling to Generate Alternatives (MGA) (DeCarolis, 2011; Trutnevyte, 2013; Voll et al., 2015) and Multi-model comparisons (Knopf et al., 2013; Tavoni et al., 2013; Weyant \& Kriegler, 2014; Kriegler et al., 2015).

Some background on these modelling techniques is provided in Table A-1 in the Annex. Most of these advanced uncertainty methods lead to a rising number of scenarios. This surely leads to a better exploration of the uncertainty space, but at the same time it has to be made sure that such studies produce relevant and transparent policy insights (Trutnevyte et al., 2016.)

This study contributes to the growing research area of uncertainty analysis in energy system models. Using the approach of a global sensitivity analysis in a national, bottom-up, optimizing energy system model, the aim is to identify which low-carbon technologies and resources have the most influence on the long-term development of the UK energy system under ambitious decarbonisation pathways. Our motivation stems from the fact that most forward looking scenarios rely on the rapid scaling up of technologies, that currently either occupy a fairly small niche, but have not yet demonstrated the capability of such growth or entered commercial markets. While it seems likely that at least one of the technologies will be able to scale up, it seems equally likely that at least one of the technologies will suffer an unforeseen setback. Our analysis aims to see how sensitive the outcomes are to the failure of one or more key technologies, what are the interactions between the technologies and at what point reaching targets may become difficult. We emphasise the relevance to policy by (1) basing the quantitative scenario analysis on consistent and, in the UK context, realistic narratives for each technology dimension; (2) limiting the analysis to a manageable number of scenarios such as to have sufficient variability to assess the effect of technology uncertainty, while still being able to analyse each scenario in detail and (3) exploring various metrics to present the results across the scenario matrix in an insightful and concise manner. The limited number of dimensions of uncertainty allows us to conduct a global sensitivity analysis by computing scenarios for the all the combinations of the combinations of parameters.

The paper is structured as follows. Chapter 2 provides an overview of the methodology, including a description of the modelling framework, the qualitative technology narratives and the approach for the sensitivity analysis. The result metrics for the quantitative scenario analysis are presented in Chapter 3 focusing on the reference case, variability in fuel use, emissions and cost indicators as well as insights 
on technology complementarity and substitutability. The paper concludes with a discussion of findings and policy implications in Chapter 4.

\section{Methodological approach}

\subsection{The national energy system model UKTM}

We use the new national UK TIMES energy system model (UKTM)(Daly et al., 2015; Fais et al., 2016a) to conduct a quantitative scenario analysis. UKTM has been developed at the UCL Energy Institute over the past two years as the successor to the UK MARKAL model (Kannan et al., 2007). It is based on the model generator TIMES (The Integrated MARKAL-EFOM System), which is developed and maintained by the Energy Technology Systems Analysis Programme (ETSAP) of the International Energy Agency (IEA) (Loulou et al., 2005).

UKTM is a technology-oriented, dynamic, linear programming optimisation model representing the entire UK energy system from imports and domestic production of fuel resources, through fuel processing and supply, explicit representation of infrastructures, conversion to secondary energy carriers (including electricity, heat and hydrogen), end-use technologies and energy service demands. Generally, it minimizes the total welfare costs (under perfect foresight) to meet exogenously defined sector energy demands under a range of input assumptions and additional constraints. The model delivers a cost optimal, system-wide solution for the energy transition over the coming decades.

The model is divided into three supply side sectors (resources $\&$ trade, processing $\&$ infrastructure and electricity generation) and five demand sectors (residential, services, industry, transport and agriculture). All sectors are calibrated to the base year 2010, for which the existing stock of energy technologies and their characteristics are known and taken into account. A large variety of future supply and demand technologies are represented by techno-economic parameters such as capacity factor, energy efficiency, economic lifetime, capital costs, O\&M costs etc. The investment cost assumptions for the most important electricity generation technologies are presented in Table A-2 in the Annex. The model also includes assumptions for attributes not directly connected to individual technologies, such as energy prices, resource availability and the potentials of renewable energy sources. UKTM has a temporal resolution of 16 time-slices (four seasons and four intra-day times-slices). In addition to all energy flows, UKTM tracks $\mathrm{CO}_{2}, \mathrm{CH}_{4}, \mathrm{~N}_{2} \mathrm{O}$ and HFC emissions. For more information on UKTM see Fais et al. (2016b).

In addition to its academic use, UKTM is the central long-term energy system pathway model used for policy analysis at the Department of Energy and Climate Change (DECC) and the Committee on Climate Change (CCC).

\subsection{Technology uncertainty dimensions}

To arrive at a comprehensive picture of the potential impacts of technology (and resource) uncertainty on the decarbonisation pathways in the UK, 5 key low-carbon technology dimensions have been chosen for the sensitivity analysis: nuclear energy, carbon capture and storage, bioenergy, renewable electricity and demand-side change. For each dimension, a consistent narrative for, both, the central case and the sensitivity variant, has been developed and then further translated into quantitative model input assumptions (Table 1).

\section{Nuclear energy $(N)$}

According to the most recent government cost estimates, nuclear energy is currently the low-carbon technology with the lowest generation costs in the UK (DECC, 2013) and is therefore at the centre of 
the government's decarbonisation strategy with a contribution of up to $75 \mathrm{GW}$ by 2050 (compared to the current $11 \mathrm{GW}$ ) according to the UK's Carbon Plan (scenario "Higher nuclear; less energy efficiency"; DECC, 2011a).

But even though nuclear power constitutes a proven technology and has contributed to electricity generation in the UK for more than five decades, a number of uncertainties surround its future development, most importantly with respect to costs and public acceptance. Nuclear power costs have recently risen considerably, leading to long delays in starting construction as well as difficulties in finding investors. The future competitiveness of nuclear power with other low-carbon technologies is far from certain (Birmingham Policy Commission, 2012; Tyndall Centre, 2013). Public acceptance of nuclear energy is generally relatively high in the UK compared to other countries (Poortinga et al., 2013), but it remains to be seen whether the possible delays and significant cost increases for the first planned new-built plant since 1995 at Hinkley C could have a deteriorating effect.

Accordingly, in the central case, assuming that investments in nuclear energy are rejuvenated and public opinion is favourable, nuclear capacity is allowed to grow to a maximum of $33 \mathrm{GW}$ until 2050 in line with the current central government estimate based on the Dynamic Dispatch Model (DDM) (DECC, 2012a) and the core scenario of the Carbon Plan (DECC, 2011a). In contrast, under the technology variant nuclear $(N)$, based on the aforementioned barriers in terms of financial investors and public acceptance, we analyze the extreme case of no new nuclear projects being realized in the UK until 2050.

\section{Carbon capture and storage $(C)$}

Carbon capture and storage (CCS) is the only technology with which the continued use of fossil fuels in electricity generation and industrial processes is compatible with a low-carbon transition. CCS is therefore seen as a crucial component of a long-term emission reduction pathway in the UK. The important role of CCS technologies had also been recognized by the UK government in their CCS Roadmap from 2012 (DECC, 2012b).

At the same time, CCS technology is at an early stage of development and has not been yet technically proven at full scale. The important risk factors concerning the future deployment include technology and constructions risk, the future competitiveness compared to other low-carbon options, the financial feasibility of CCS projects, infrastructure and storage risks, the regulatory framework, as well as the public acceptance of CCS (Watson et al., 2012). The high uncertainty is reflected in the current political situation in the UK where the CCS Commercialisation Competition, providing £1 billion capital funding, has just been cancelled (HM Government, 2015).

Thus, in the central case of this sensitivity analysis, it is assumed that these challenges are overcome and CCS technologies in electricity generation, industry and hydrogen production are commercially available from 2020 onwards (CCS plants with bioenergy from 2030). In addition, for all CCS technologies an annual capacity growth constraint of $10 \%$ is applied. In light of the considerable risks, the technology variant carbon capture and storage $(C)$ assumes that CCS technologies will unavailable in the UK before 2050 .

\section{Bioenergy (B)}

Bioenergy can play a crucial role in decarbonisation strategies as it is highly versatile. With usage options in electricity, heat and transport, biomass offers dispatchable, predictable and controllable energy output. Moreover, the potential of biomass with CCS to deliver negative emissions is often highlighted as a crucial carbon reduction technology (IPCC, 2014). On the other hand, concerns are voiced regarding the sustainability of biomass production for energy and its impacts on food production 
and other environmental targets, such as biodiversity (Immerzeel et al., 2014). Additionally, the actual emission reductions achievable with bioenergy may be considerably lower if the lifecycle impacts are taken into account (IEA, 2011 and IEA, 2012).

The bioenergy potentials and costs in this scenario analysis are based on the Committee on Climate Change's Bioenergy Review for the UK (CCC, 2011a). In our central case, we use the medium scenario "Extended Land Use" with total bioenergy potential reaching about 1300 PJ per year in 2030 compared to a biomass use of about $400 \mathrm{PJ}$ in 2015. The potential covers both imports and domestic resources of dedicated energy crops, forestry and agricultural residues as well as waste. In this scenario, less than $10 \%$ of the UK's arable land would be used for dedicated energy crops. This potential is then held constant until 2050 assuming that both the maximum sustainable yield for domestic resources and the maximum import volume are reached (in contrast to the CCC report where falling bioenergy imports are expected). In the technology variant bioenergy $(B)$, the projection for the domestic biomass resources is based on the scenario "Constrained Land Use", reflecting lower crop yields and tighter social and environmental constraints on biomass production where only $5 \%$ of the UK's arable land are used for dedicated energy crops. We also assume that no bioenergy imports are available in the UK from 2020 onwards, limiting the available biomass to around 380 PJ per year over the model horizon. In both cases, biomass resources are assumed to be carbon-neutral following the bioenergy emission accounting approach of the EU Renewable Energy Directive (EC, 2009). The optimization approach is free to choose where and when the bioenergy is used, allowing us to explore the competition between different sectors and technologies and the most cost-efficient deployment areas.

\section{Renewable electricity $(R)$}

The UK has considerable potential for renewable electricity generation, most importantly for onshore and offshore wind energy (DECC, 2011b). As of writing, the UK currently has the highest installed capacity of offshore wind turbines in the world (DECC, 2014a) and has experienced significant growth in solar PV installations (BEIS, 2016). However, several issues affecting the UK renewable industry need to be highlighted. Most importantly, concerns are raised regarding the stability of government support (Raconteur, 2014; renewableUK, 2015a), most clearly demonstrated in the recent deep cuts to solar and onshore wind subsidies (DECC, 2015). The change in subsidy level has strongly affected local supply chains. Wind power faces considerable local opposition in the UK, mostly due to the visual impacts (McLaren Loring, 2007; Haggett, 2011). Uncertainty also exist regarding the future cost development of both less mature technologies, such as marine or geothermal energy, and more mature technologies such as offshore wind farms as they move to more challenging environments further away from shore (Heptonstall et al., 2012; Higgins and Foley, 2014; Perveen et al., 2014). Lastly, the issue of integrating large amounts of intermittent and decentralized renewable generation into the UK power system needs to be recognised, leading to additional costs and possible constraints on their overall use (Strbac et al., 2015).

In the scenario analysis, both the future potential and cost assumptions are varied. In the central case, a high technical resource potential (> $400 \mathrm{GW}$ ) and learning effects are implemented for renewable sources in the UK, while under the technology variant renewable electricity $(R)$ the renewable potential is restricted to $51 \mathrm{GW}$ (without hydropower) - reflecting acceptability as well as system integration issues - and costs remain at the current level (see Table A-3 in the Annex for more detail).

Some limitations need to be mentioned regarding the representation of intermittent renewables in UKTM. While the necessary back-up capacity for intermittent renewables is accounted for, it has to be noted that the spatial (UK as one region) and temporal granularity of our model (with 16 time-slices) is not ideal for capturing the impacts of decentralized generation as well as the interplay between varying demand and supply. Some system effects and costs (in terms of required storage capacity, grid 
expansion and demand response) are not fully reflected in a whole energy system model such as UKTM requiring details operational simulation.

\section{Demand-side change $(D)$}

While the other technology dimensions focus primarily on supply technologies or resource availability, the dimension of demand-side change $(D)$ is introduced to acknowledge the importance of the demand side for emission mitigation. While a variety of studies have identified substantial abatement potentials at comparatively low or even negative costs in the industry, buildings and transport sectors (cf. for example McKinsey, 2007 and IEA, 2015b), in reality many of these potentials are not exploited and the rate of diffusion of novel technologies is considerably lower than what would be expected from the socially cost-optimal perspective. This phenomenon, referred to as the energy paradox or the energyefficiency gap, can be explained by a variety of market failures and barriers, such as limited information, transaction cost, risk adversity or market heterogeneity (Jaffe \& Stavins, 1994).

In energy system optimisation models, such barriers are incorporated by either limiting market share, applying hurdle rates or constraining the diffusion rate of innovative technologies (Mundaca et al., 2010; Dodds \& McDowall, 2014; Yang et al., 2015).

In this scenario analysis, the dimension $D$ focuses on the diffusion rates of demand-side technologies and the demand response to changing energy service prices. Historic diffusion rates in energy systems have been analysed in several studies (cf. for example Grübler et al., 1999 and Wilson et al., 2013). Usually, growth rates between $10 \%$ and $15 \%$ are applied to all new demand technologies in UKTM. However, given the evidence of diffusion rates of less than ten percent in some studies (cf. for example Höök et al., 2012), these rates are halved to $5 \%$ to $7.5 \%$ for innovative and highly efficient demandside technologies under the technology variant $D^{2}$. Moreover, the long-run own-price elasticities that are attached to the different energy service demand categories, are lowered to -0.01 to -0.5 instead of 0.03 and -0.7 in the central case (based on Pye et al. (2014)).

2 Lower diffusion rates are applied to:

- Buildings: heat pumps, solar heating systems, micro-CHPs, conservation technologies; hydrogen pipelines to the residential and services sectors are disabled

- Transport: hydrogen and electric (including plug-in hybrids) vehicles

- Industry: all process technologies which are beyond the current state of the art; hydrogen as well as highefficiency boilers 
Table 1: Overview of technology dimensions

\begin{tabular}{|c|c|c|}
\hline Dimension & Central Case & Sensitivity \\
\hline Nuclear (N) & $\begin{array}{l}\text { New nuclear capacity limited to } \\
33 \mathrm{GW} \text { until } 2050\end{array}$ & No additions after 2010 \\
\hline $\begin{array}{l}\text { Carbon capture } \\
\text { and storage }(\mathrm{C})\end{array}$ & $\begin{array}{l}\text { - Capacity growth limited to } 10 \% \text { p.a. } \\
\text { - Maximum capacity of } 45 \mathrm{GW} \text { in } \\
\text { electricity generation } \\
\text { - Available in } 2020 \text { ( } 2030 \text { for bio-CCS) }\end{array}$ & $\begin{array}{l}\text { CCS does not become available in the } \\
\text { UK }\end{array}$ \\
\hline Bioenergy (B) & $\begin{array}{l}\text { Total potential (imports + domestic): } \\
1300 \text { PJ per year }\end{array}$ & $380 \mathrm{PJ}$ per year \\
\hline $\begin{array}{l}\text { Renewable } \\
\text { electricity }(R)\end{array}$ & $\begin{array}{l}\text { - High technical potential (>400 GW) } \\
\text { - learning effects for all technologies }\end{array}$ & $\begin{array}{l}\text { - } \text { Restricted potential ( } 49 \mathrm{GW} \text { ) } \\
\text { - higher cost assumptions for offshore } \\
\text { wind \& solar PV } \\
\text { - marine \& geothermal not available }\end{array}$ \\
\hline $\begin{array}{l}\text { Demand-side } \\
\text { change (D) }\end{array}$ & $\begin{array}{l}\text { Medium elasticities (-0.03 to }-0.7) \\
\text { growth constraints of } 10 / 15 \% \text { p.a. } \\
\text { on all technologies }\end{array}$ & $\begin{array}{l}\text { - Low elasticities }(-0.01 \text { to }-0.5) \\
\text { growth constraints lowered to } 5 \% \text { / } \\
7.5 \% \text { for innovative and energy- } \\
\text { efficient technologies }\end{array}$ \\
\hline
\end{tabular}

\subsection{Scenario matrix}

The quantified descriptions of the five technology dimensions (Table 1) are implemented in a comparative scenario analysis with UKTM. To explore the uncertainty space of the availability of the key low-carbon technology options in the UK, we conducted a global sensitivity analysis with scenarios for all possible combinations of the five dimensions. With 5 dimensions, each with 2 possible values, a scenario matrix of $32\left(2^{5}\right)$ scenarios is established. This allows us to assess both the individual effects of each dimension, and also to understand the interaction effects of the availability of several lowcarbon options. In the results chapter, the scenarios are denoted by the one-letter abbreviation of each dimension that is restricted, e.g. the scenario where only nuclear energy is restricted is labelled $\mathrm{N}$, the scenario where all 5 dimensions are restricted is labelled NCBRD.

Apart from the technology assumptions described in Table 1, the standard input parameters of UKTM are used in the scenario analysis (Fais et al., 2016b). The projections for energy service demands are based on government forecasts of the development of household growth, employment, transport demand etc. and are in line with average annual growth rates of $2.1 \%$ for GDP and $0.4 \%$ for population (based on the DECC EEP model ${ }^{3}$ and ONS (2013) (low migration variant)). The assumptions for fossil fuel prices are taken from DECC (2014c). With respect to future technology costs, exogenous learning rates are applied, especially in the case of less mature electricity and hydrogen technologies, assuming that the UK is a price taker for globally developing technologies. A global discount rate of 3.5\% p.a. for the first 30 years and 3\% afterwards is used based on HM Treasury (2011). In addition, sectorspecific discount rates are included to reflect the varying private costs of capital by sector (10\% for all energy supply sectors as well as the industry, agriculture and service sectors, $7 \%$ for transport and 5\% for the residential sector; based on Strachan \& Usher (2010) and CCC (2011)).

All scenarios take the UK legislation on GHG emission limits into account, comprising the four fiveyearly carbon budgets that have been fixed so far until 2027 (CCC, 2013) and the long-term target of an $80 \%$ reduction until 2050 compared to 1990 (HM Government, 2008). In order to give the model flexibility with respect to the timing of emission reductions after the already implemented carbon

3 A description of the DECC EEP model can be found in DECC (2014b). The actual model runs underlying the demand projections for UKTM have not been published. 
budgets, the long-term target is applied via a cumulative budget constraint covering the period from 2028 to 2050 which results in the same total quantity of emissions as would a linear reduction pathway to $80 \%$ until 2050 . Thus, the model also has the option to comply with the cumulative budget through early action, i.e. by realizing deeper emission cuts in earlier periods allowing a higher emission level in later periods. This means, that the cumulative target can be fulfilled without actually reaching an $80 \%$ reduction until 2050 if in earlier periods the emission reduction exceeds the linear reduction pathway.

\section{Results of the uncertainty analysis}

This section gives an overview on the most important outcomes of the uncertainty analysis focusing on the variability between the scenarios and the issue of complementarity or substitutability of technologies. First of all, it needs to be pointed out that for three of the most extreme cases, NCBR, NCRD and NCBRD, no feasible model solution fulfilling the given constraints (most importantly the cumulative carbon constraint) can be generated such that these scenarios are excluded from the results analysis. This result should not, however, be forgotten, as it suggests that with our assumptions the UK's carbon target can only be met if at least some of the technologies in our analysis perform according to expectations and have the ability to diffuse strongly. The infeasible cases highlight the circumstances under which the UK's achievement of its climate goals would be highly unlikely. If all other analysed technology options fail, under a higher biomass potential or less restricted demand-side diffusion, the model fails to reach the UK's carbon target under the given scenario assumptions.

\subsection{The reference case}

In order to set the reference point for the uncertainty analysis, this section briefly describes the energy system results for the reference case, in which all technologies follow the Central Case assumptions (Figure 1). The most significant changes occur in the electricity system with a complete phase-out of electricity generation from coal by 2025 . With respect to electricity generation, the contribution of natural gas is also gradually reduced to almost zero by 2050 , while a capacity of $16 \mathrm{GW}$ of gas-powered plants is still required in 2050 as back-up capacity. In 2050, generation is strongly dominated by nuclear power (66\%) and bio-CCS (20\%), whereas wind power and other renewable source only play a minor role. Only limited electrification of the end-use sectors can be observed in the reference case with the total amount of electricity generated being at almost the same level in 2050 as in 2015 . Until 2025, there is even a reduction in electricity demand due to efficiency gains (most importantly for lighting), a reduction in the use of night-storage heaters and falling demand levels in the industrial sector.

Given the significant decarbonisation efforts in the electricity system, less drastic adjustments are required in the end-use sectors. Final energy consumption is reduced by about $16 \%$ between 2015 and 2050 with the strongest reduction in the industrial sector. In terms of fuel use, final energy demand is still dominated by fossil fuels with a share of $62 \%$ in 2050 (compared to $81 \%$ in 2015). Due to the limited availability of biomass and its strong use for bio-CCS in the supply side, the role of bioenergy in the end-use sectors remains comparatively small. A gradual uptake of hydrogen, produced in centralized CCS plants and covering about $11 \%$ of final energy demand in 2050, occurs in car and light duty vehicle transport as well as in some industrial sectors for low-temperature heat generation. Overall, this relates to a reduction in primary energy consumption of 5\% between 2015 and 2050. Total fossil fuel consumption is reduced by almost $40 \%$ in this period, but still covers more than half of primary energy consumption in 2050. The substantial reduction before 2025 is predominantly due to the phaseout of inefficient coal power generation and a declining energy demand in the industry sector (mostly because of falling production levels). 


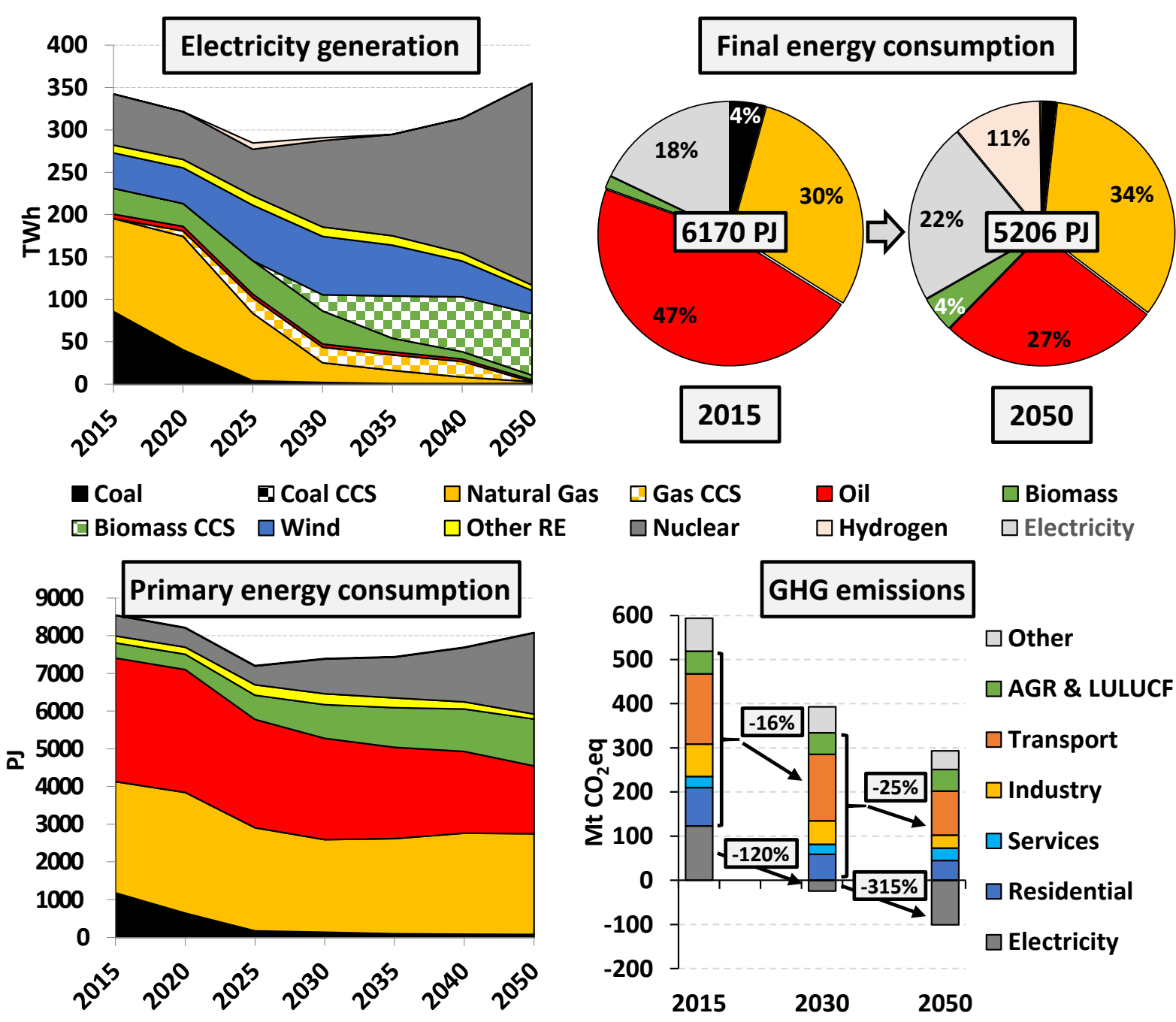

Figure 1: Overview on the reference case

As explained in Section 2.3, implementing the $80 \%$ emission reduction target as a cumulative budget constraint gives the optimization approach more freedom with respect to the timing of the mitigation efforts. In the reference case, total GHG emissions decline by $76 \%$ by 2050 compared to 1990 . The reference case complies with the cumulative carbon budget constraint and favours early action. Higher emission cuts are realised than a linear reduction path would imply, especially between 2030 and 2040, so avoiding investments in additional costly abatement options to reach the ambitious level of $-80 \%$ in 2050. As expected, emission mitigation is dominated by the electricity sector which is carbon-neutral by 2030 and accounts for $100 \mathrm{Mt}$ of $\mathrm{CO}_{2}$ eq of negative emissions in 2050 (due to the use of carbonneutral biomass with CCS). With respect to the end-use sectors, the highest reductions between 2015 and 2050 are achieved in the industry (59\%) and residential sector (49\%) such that in 2050, the remaining GHG emissions are dominated by the transport sector. The carbon price (given in the model as the shadow price of the carbon constraint) rises from $£ 27 / \mathrm{tCO}_{2} \mathrm{eq}$ in 2020 to $£ 244 / \mathrm{t} \mathrm{CO}_{2} \mathrm{eq}^{4}$ in 2050 .

It becomes obvious that in the reference case, decarbonisation is highly dependent on large-scale technologies such as nuclear power plants and bio-CCS. This enables a delay to mitigation efforts in the end-use sectors, most importantly in the transport sector. Yet, from a policy perspective, this can be an unbalanced and especially risky strategy as it depends on technologies and combination of

4 All monetary values stated in this paper are in real terms, with 2010 as base year. 
technologies and resources with highly uncertain future costs and availability, which in some cases, have so far not even reached commercialization.

\subsection{Insights on variability across the whole scenario matrix}

\section{Variability in fuel use}

Exploring the variability in fuel use across the entire scenario matrix provides insights into the longterm uncertainty of decarbonisation pathways as a function of technology availability and performance. The analysis focuses on the variability at the endpoint of the model horizon, as represented in the boxand-whisker plots for the most important fuel demands in 2050 shown in Figure 1.

The strongest variability in 2050 can be observed for the use of natural gas, both in terms of the interquartile range which spans 1,500 PJ and in terms of the minimum $(630 \mathrm{PJ})$ and the maximum value (5,500 PJ). Generally, restricting the various dimensions has a dampening effect on the use of natural gas (i.e. the median value is below the value in the reference case). As can be expected, the nonavailability of CCS has the strongest negative impact, whereas the gas demand is increased in scenarios which feature CCS but have restrictions on other low-carbon electricity options (i.e. scenarios with R and $\mathrm{N}$ ). However, while there are scenarios with increased gas use in electricity generation, final use of gas is reduced in almost all of the restricted cases, as many of the restrictions imply that stronger mitigation efforts are required on the demand-side compared to the reference case. Taking into account the uncertainty in technology development, this result suggests that the pressure on demand side mitigation may be even stronger than normally shown by scenarios exercises in which all technologies perform as expected.

Given the relevance of oil products in the transport sector, there is significantly less variability in oil use across the scenarios. Compared to 2010, oil demand is reduced between $38 \%$ and $74 \%$ with road transport fully covered by hydrogen and electricity in the more restricted cases, but substantial shares of petroleum products still required in aviation and shipping due to the limited availability of biofuels. Use of oil is at its lowest when low-carbon electricity generation is strongly restricted (scenario NCR), such that the transport sector has to contribute strongly to emission mitigation (through a high use of hydrogen and a small contribution of biofuels).

While no clear trend towards stronger electrification can be observed in the reference case, emission mitigation through a higher use of electricity becomes more relevant in the restricted scenarios, with a variety of factors and combination of factors incentivising stronger electricity use. Both a limitation of the potential for negative emissions on the supply side (through restrictions on CCS and/or the bioenergy potential) and constraints on the rate of demand-side change lead to a higher electrification of the end-use sectors with the possibility of a doubling of electricity demand compared to 2010 in some of the extreme cases. The most significant increases in electricity use occur in the residential sector through an increased use of heat pumps, which provide up to $61 \%$ of residential heat demand in 2050 . In some of the most restricted scenarios (CBRD and NCBD), electric vehicles cover up to $80 \%$ of car travel demand in 2050, but in general decarbonisation in the transport sector relies much more strongly on hybrid vehicles and hydrogen for heavy duty trucks. Less clear electrification trends can be observed in the industry and services sector. Electricity prices are not set exogenously but are determined within the model as the marginal costs of electricity generation. Restricting low-carbon generation options leads, as can be expected, to a significant increase in these prices. However, in some of the more restricted scenarios, electricity use will increase anyway as electrification becomes one of the last options for emission mitigation. 


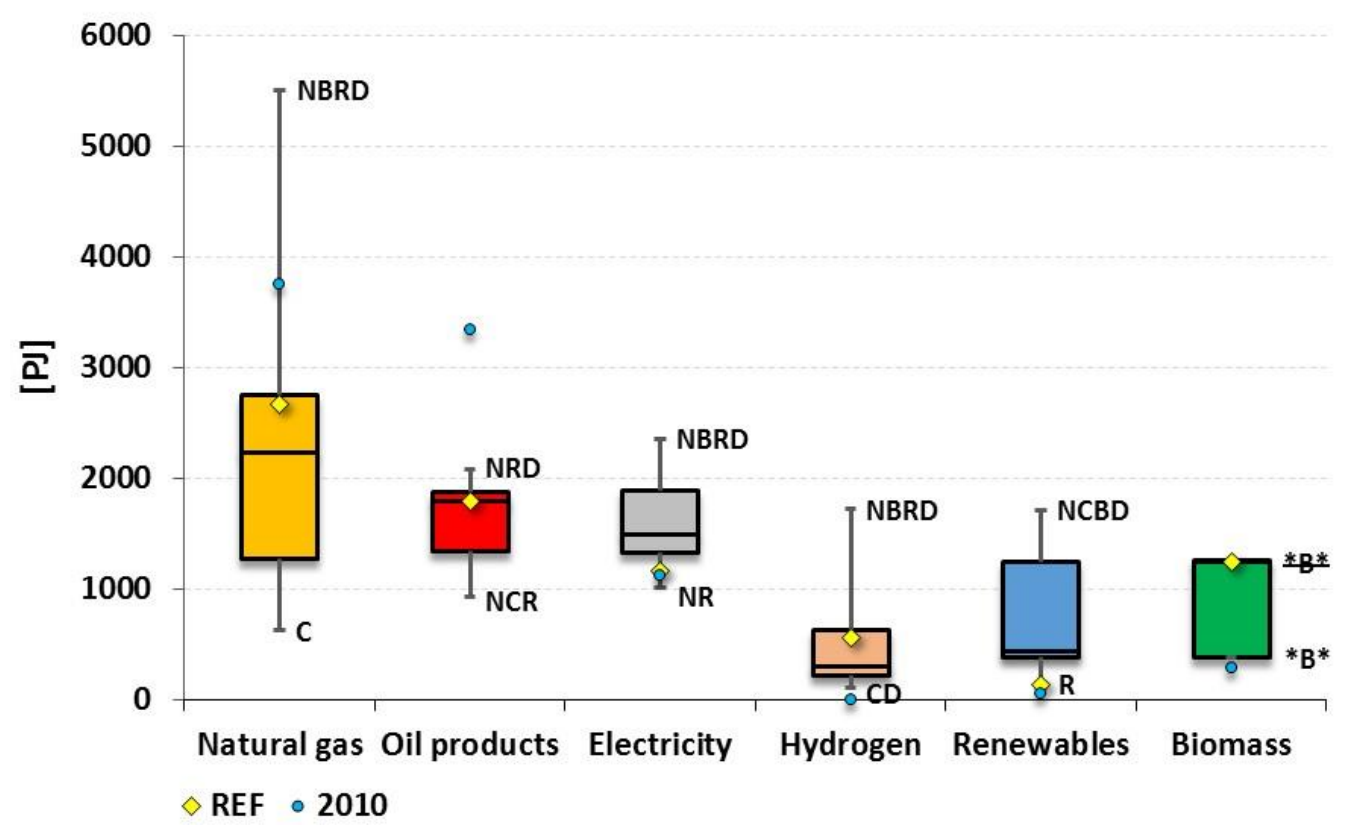

Figure 2: $\quad$ Box-and-whisker plots on fuel use in 2050 across all 28 scenarios $^{5}$

The use of hydrogen, produced from biomass and/or in plants equipped with CCS, constitutes an alternative decarbonisation strategy for the demand side. However, the uncertainty analysis shows that most of the restricted scenarios have a lower demand for hydrogen in 2050 than in the reference case. The CCS dimension has the strongest impact with hardly any hydrogen entering the UK system in scenarios without CCS. Apart from that, the dimension of demand-side change limits the uptake of hydrogen technologies, especially in the transport sector. The highest contribution to final energy demand (with a maximum of $18 \%$ in 2050) occurs in the cases with restricted biomass potentials. Restricted availability of biomass limits the deployment of bio-CCS in electricity generation and puts more pressure on the end-use sectors to decarbonise.

To explore the use of renewable sources across the uncertainty scenario matrix, biomass and other renewable energies are included in the fuel-specific box-and-whisker plots in Figure 2 and the variability in the renewable share in gross final energy consumption, differentiated by electricity, heat and transport, is depicted in Figure 3 (left-hand side). Note that the shares in heat and transport only contain the direct use of renewable resources in these sectors and not the use of renewable electricity. To emphasise the importance of biomass in decarbonisation strategies, is the results show how biomass is fully exploited in all scenarios up to the maximum available in any scenario. However, the other restrictions placed on the other dimensions have the effect of influencing where the biomass is used. For example, while biomass is mainly used in electricity generation if CCS is available, given the opportunity to generate negative emissions through bio-CCS, an almost complete shift to the end-use sectors, most importantly in the industry and commercial sector occurs in scenarios without CCS. Bioenergy, if not further restricted, can then cover up to $22 \%$ of total final energy demand in 2050.

While other renewables do not play a significant role in electricity generation in the reference case, their contribution rises in almost all of the restricted cases. Substantial amounts of on- and offshore wind energy are deployed as soon as one of the other low-carbon electricity options is restricted, reaching an installed capacity of up to $105 \mathrm{GW}$ in 2050 (in cases with high availability of renewable options).

5 All box-and-whisker plots shown in this paper depict the interquartile range in the box, while the whiskers represent the maximum and minimum value. 
Sizeable amounts of solar energy, with a maximum capacity of $45 \mathrm{GW}$, are only utilized in some of the more restricted cases (where both nuclear energy and CCS are unavailable), while marine energy only reaches a non-negligible role in the most restrictive cases for the electricity system (without limiting the renewable dimension, i.e. NCB and NCBD). Accordingly, the renewable share in electricity generation varies substantially between $18 \%$ and $97 \%$ in 2050, with an intermittent share of up to $80 \%$. A variety of studies have shown that renewable shares of up to $80 \%$ would be technically feasible (Pfenninger \& Keirstead (2015), CCC (2011b) for the UK, European Climate Foundation (2010) for the European Union) - at a manageable cost. The necessary back-up capacity for intermittent renewables reaches up to $50 \mathrm{GW}$ of natural gas or hydrogen fuelled gas turbines in some of the scenario runs. As mentioned above, other system effects and costs of the increase in intermittent renewables are not fully reflected in a whole energy system model like UKTM. In light of the strong competition for bioenergy resources, biofuels for end-use do not become a central decarbonisation strategy in any of the scenarios. The renewable share in heating is strongly dominated by the use of heat pumps in buildings, while high contributions from biomass are only obtained in scenarios where bio-CCS is not available. On the whole, the renewable share in gross final energy consumption varies between $14 \%$ and $61 \%$ in 2050 and is at its lowest in scenario R.

Finally, we analyse the reduction in final energy consumption across the scenario matrix as the last dimension on variability in fuel use (right-hand side of Figure 3). The reduction in final energy demand by 2050 compared to 2010 lies between $13 \%$ and $37 \%$. The strongest reduction efforts occur in two types of scenarios: (1) in cases without CCS, but strong potential for low-carbon electricity generation and (2) in very restricted cases. While in the first group the residential sector is the most relevant for the additional savings, the transport sector plays a pivotal role in the very restricted scenarios. Constraining demand-side change only has a dampening effect on energy efficiency in the less restricted cases. Compared to the reference case, the strongest additional savings are realized in the residential and transport sector, whereas in the industrial sector the potential for energy efficiency measures is already almost fully exploited allowing further demand reductions only in a few extreme cases. In contrast, based on the underlying growth in the sector's GVA, a considerable increase in energy demand is still expected in the services sector, ranging between $17 \%$ and $33 \%$ in 2050 . Interestingly, the technology restrictions tend to raise the commercial fuel consumption, which is mainly driven by the lower demand elasticities and restricted uptake of efficiency measures under variant $D$ as well as an increased use of biomass in scenarios without CCS.

From a policy perspective this sensitivity analysis suggests important hedging strategies to achieve long-term deep decarbonisation. Even if the usual reference case with broad technology availability proposes a strong focus on the electricity sector with large-scale technologies like CCS and nuclear, the sensitivity analysis points towards a stronger use of renewable sources as well as stronger efforts in terms of energy efficiency in the buildings and transport sectors to ensure that long-term mitigation targets are reached in the presence of technology uncertainty. 

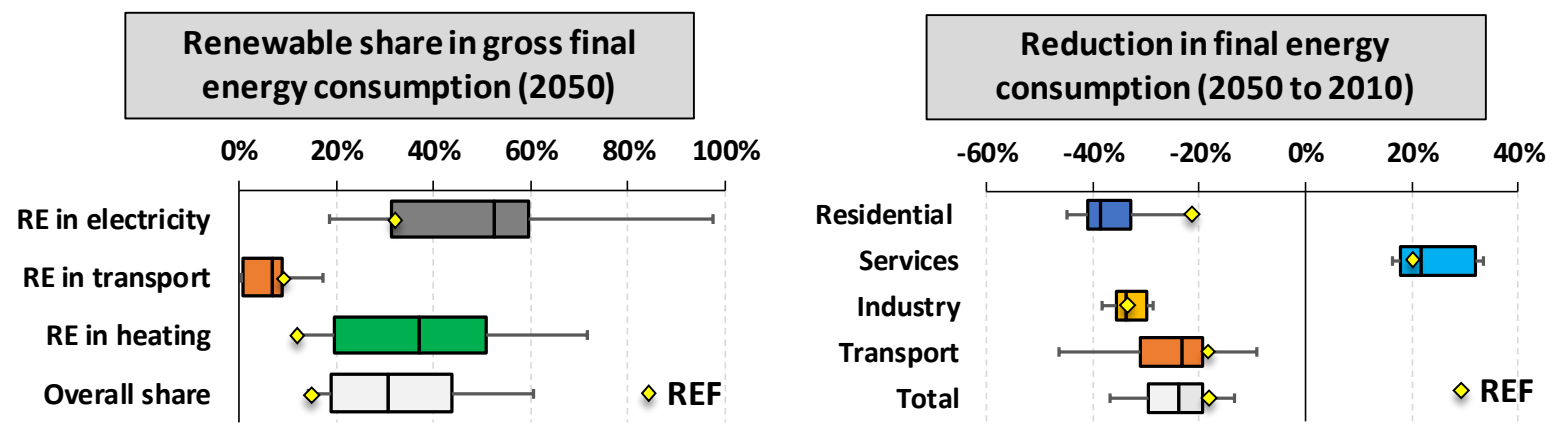

Figure 3: Box-and-whisker plots on the renewable share in gross final energy consumption (left) and reduction in final energy consumption (right) across all 28 scenarios

\section{GHG emission reduction}

With respect to emission mitigation we first investigate the overall reduction trajectory. Implementing the $80 \%$ reduction target for 2050 as a cumulative budget (between 2028 and 2050), offers insights into the dependency of the optimal timing of the abatement actions on the technology availability. Figure 4 shows the minimum and maximum GHG emission in each period as well as the two most extreme pathways (in terms of emission reduction in 2050). There is a considerable spread in the reduction reached in 2050 from $67 \%$ (NCR) to $76 \%$ (REF) compared to 1990. Please note that all scenarios with a feasible solution comply with the cumulative budget set in the model. However, none of the scenarios fulfils the budget by reaching the politically set $80 \%$ reduction target in 2050 . Instead, early action is favoured such that especially between 2030 and 2040 higher emission cuts are realised than a linear reduction path would imply thereby avoiding investments in additional, costly abatement options in 2050 (as reflected in the difference between the hypothetical linear reduction path way shown by the dotted line and the actual emission pathways shown in Figure 4). The tendency for early action clearly increases with the number of technology restrictions in the scenarios. This highlights that bringing forward ambitious mitigation efforts is a clear hedging strategy against technology failure. Note that more scenarios would be infeasible if the climate target was implemented by a fixed linear reduction pathway such that the model would have to reach $-80 \%$ by 2050 . The still significant emission level in the more restricted cases (around $250 \mathrm{Mt} \mathrm{CO}$ eq in 2050) also raises concerns regarding the ability of the system to arrive at net-zero carbon emissions in the long term.

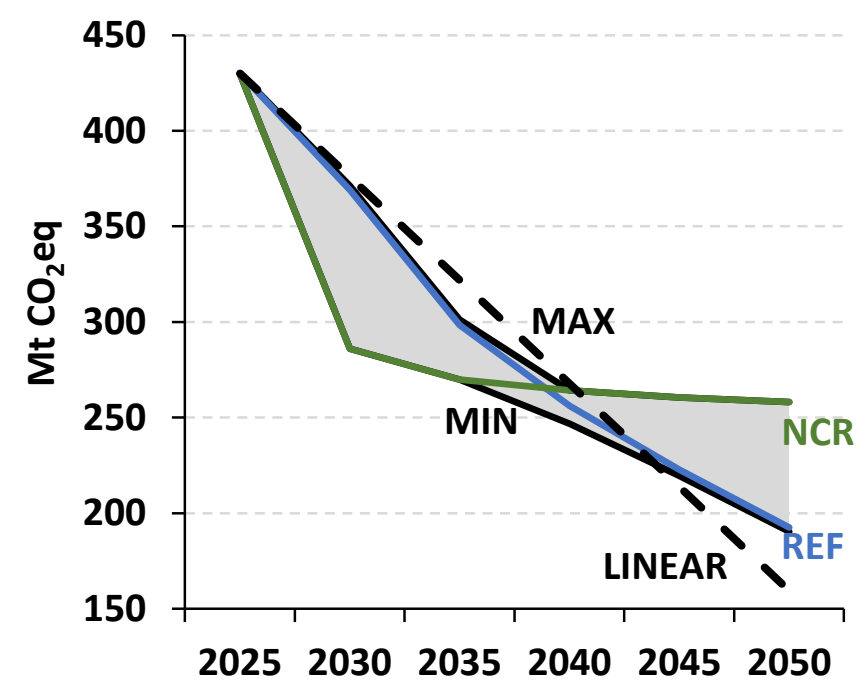

Figure 4: Range in GHG emission reduction pathways across all 28 scenarios ("LINEAR" shows the hypothetical linear reduction pathway to reach an actual $-80 \%$ reduction in 2050 ) 
Strong variations can be observed in the sector-wise contribution to emission reduction across the 28 scenarios (Figure 5). While the electricity sector reaches carbon-neutrality by 2035 in all scenarios, the long-term ability to generate negative emissions through bio-CCS strongly depends on the availability of CCS and biomass. In the residential sector, mitigation efforts increase in almost all restricted cases compared to the reference case, especially through the exploitation of all available conservation measures and stronger electrification. The service sector exhibits the highest level of variation, even with the possibility of an increase in emissions compared to 2010 in cases with limited demand-side change (including higher demand levels) and electrification potential. In the industrial sector, increased mitigation efforts occur especially in the cases with limited biomass availability, but good potential for low-carbon electricity generation. In contrast, particularly in the very restricted cases without CCS, the industry sector's contribution to emission abatement is limited compared to the central case. The transport sector is the only end-use sector that still makes a sizeable contribution to GHG emissions in all scenarios in 2050. Contrary to the other end-use sectors, transport sector abatement efforts increase in most of the very restricted cases compared to the reference case through a stronger focus on efficiency measures.

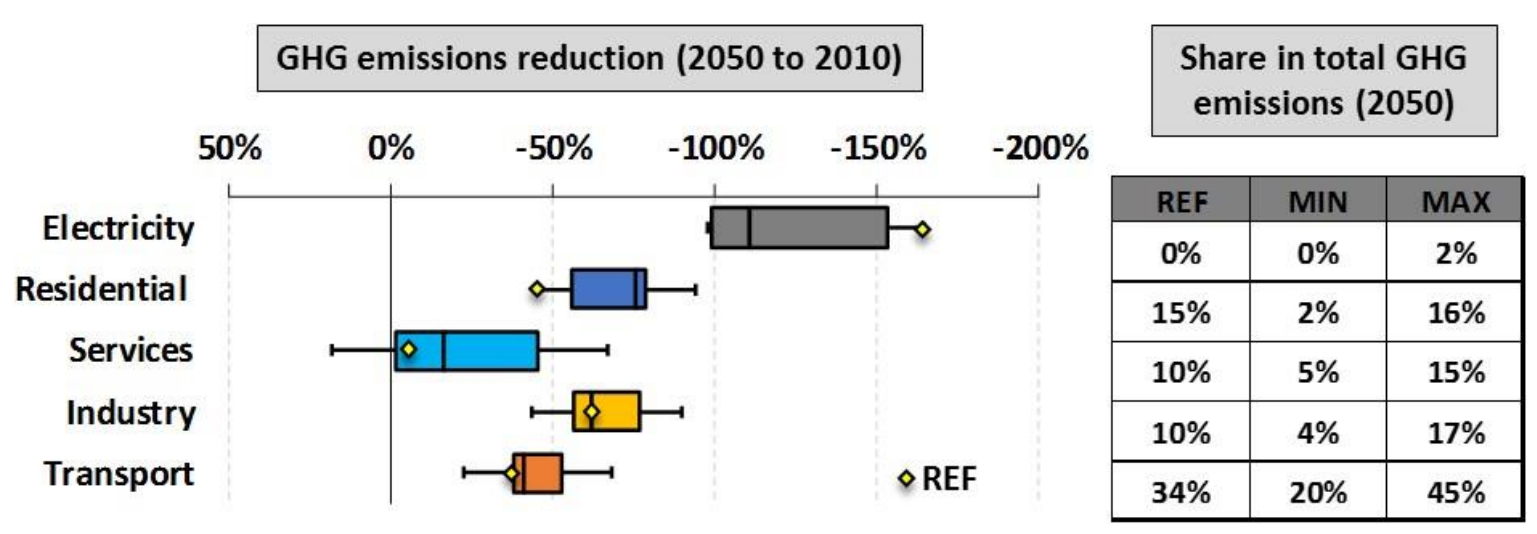

Figure 5: $\quad$ GHG emission reduction (left) and share in total emissions in 2050 (right) by sector across all 28 scenarios

\section{Cost indicators}

Apart from technology deployment and fuel use, the model results also allow a comparison of the different scenarios in terms of the implications for costs. Two types of cost metrics are analysed: (1) total societal welfare costs, which are defined as the net total surplus of producers and consumers and comprise the entire costs of a specific energy system in a certain region and a certain period, covering capital costs for energy conversion and transport technologies, fixed operating and maintenance costs as well as fuel and certificate costs; (2) the carbon price, given in the model as the shadow price of the budget constraint on GHG emissions.

In order to assess the importance of the single or combined effect of the various technology dimensions, we examine the change in cumulative welfare costs compared to the reference case (Figure 6). The cumulative cost increase is still relatively low (up to $2.4 \%$ compared to REF) in the scenarios where only one dimension is restricted. While limiting renewable electricity options has little impact, the strongest additional cost burden results from constraining the availability of CCS or biomass. Interestingly, given its strong deployment in the reference case, removing nuclear energy from the available technology options has no significant cost impact since other low-carbon electricity options, most importantly wind energy, are available at similar cost levels. 
Looking at the cases with two restrictions shows that the combined cost effect of two dimensions is usually higher than the sum of the two individual effects, with the exemption of scenario $\mathrm{CB}$, as the principal effect of both these dimensions is limiting the deployment of bio-CCS plants. The strongest cost burden (up to $4.4 \%$ compared to REF) is caused by a combination of the dimensions $\mathrm{C}$ or $\mathrm{B}$ with a limited demand-side change (D) - putting strong constraints both on the supply and demand side. Among the scenarios with three technology restrictions, the highest impact on welfare costs is induced either by severely limiting low-carbon supply-side options (case NCR) or by a combined constraint on crucial supply- and demand-side options (case CBD).

The extreme cases with four technology restrictions demonstrate which of the dimensions are crucial to keep the system-wide cost impacts at a moderate level when all other analysed technology options are constrained. For the three cases with a feasible solution, the increase in cumulative welfare cost, compared to the reference case, is less than $7 \%$ in case NBRD and around $13 \%$ in case NCBD revealing that both the availability of CCS and renewable electricity options would keep the cost increase below $15 \%$. In contrast, costs increase a lot more in the case with nuclear energy (CBRD), while reaching the long-term emissions target is not even feasible with a higher biomass potential or less restricted demandside change when all other large-scale supply-side options fail. This emphasizes the importance of the electricity sector in decarbonisation efforts as the long-term target can only be complied with if at least one of the central low-carbon electricity options is available at a significant level.

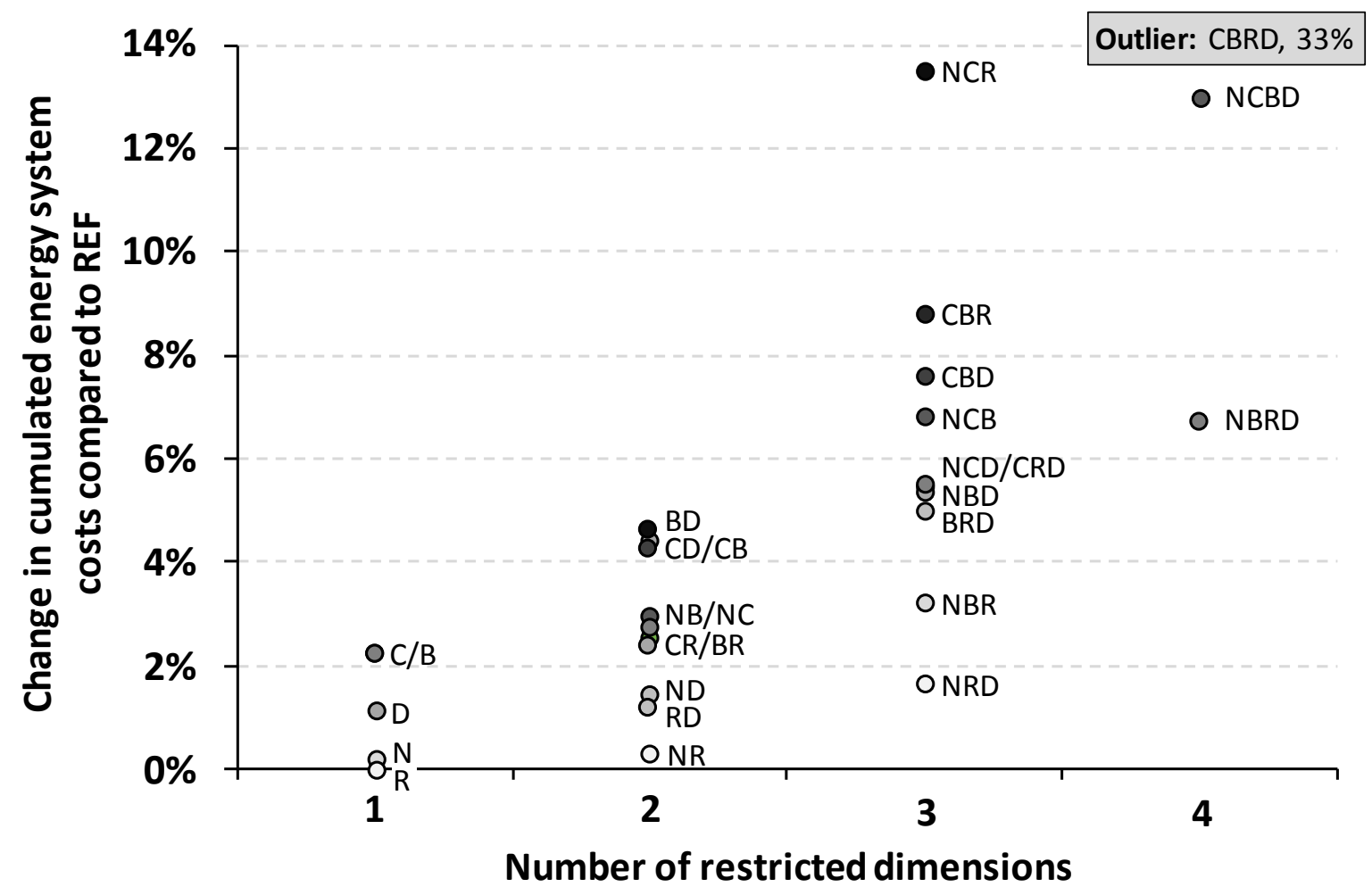

Figure 6: Change in total welfare costs (discounted, cumulated from 2010 to 2050) compared to the reference case

Similar to societal welfare costs, carbon prices vary considerably across the scenario matrix with values in 2050 of $£ 244 / \mathrm{t} \mathrm{CO}_{2}$ eq in the central case and $£ 7000 / \mathrm{t} \mathrm{CO} \mathrm{CO}_{2}$ in scenario NRC (see Table A-4 in the Annex). Regarding the scenarios with 4 technology restrictions, the carbon price in scenarios NBRD and NCBD is significantly lower than in NRC (with $£ 1500 / \mathrm{tCO}_{2} \mathrm{eq}$ and $£ 3100 / \mathrm{tCO}_{2} \mathrm{eq}$ ), highlighting once more the importance of having either CCS or renewable electricity options available to limit the 
decarbonisation costs. The scenario CBRD is a clear outlier, reaching a carbon price of almost $£ 38,000 / \mathrm{tCO}_{2} \mathrm{eq}$ in 2050 . This also shows that the carbon price, being at the margin, is much more sensitive to technology changes than the total welfare is. Adding, for example, a biomass or CCS restriction on top of any combination of other restrictions (including none - the central case) always at least doubles the carbon price. Please note that the carbon price would be significantly higher, if the carbon target was implemented by enforcing an actual reduction of 80\% until 2050 (and a linear reduction pathway) instead of the cumulative budget approach used in this analysis. The results of the carbon price also raise concerns regarding the political feasibility of reaching the long-term climate goals in a technology-constrained world. Even if all of the scenarios shown in Figure 6 complying with the cumulative carbon budget were technically feasible, the resulting carbon prices would in most likelihood not be politically enforceable (cf. also Strachan \& Usher, 2012).

The ranking of scenarios according to welfare cost or carbon price are generally quite similar. A few noteworthy exemptions provide some indications with respect to the shape of the abatement cost curve. For example, the scenarios CR and CBR rank much worse in terms of carbon price than welfare costs indicating a steep abatement cost curve, while for the scenarios BD and NBD it's the opposite case.

We finish our discussion on costs with regression results for the cumulated welfare costs, with the dimensions and their interactions as independent variables ${ }^{6}$. The coefficients in Figure 7 give an estimate of how much the existence of given scenario dimensions, or the interactions between dimensions, adds to the cost metric across the full scenario set. CBD, for example, would refer to the specific interactions effects between drivers $\mathrm{C}, \mathrm{B}$ and $\mathrm{D}$, excluding the effects these drivers have by themselves and the interaction effects the pairs of these drivers have (i.e. $\mathrm{CB}, \mathrm{CD}, \mathrm{BD}$ ). Thus, the numbers in Figure 7 can be interpreted as follows: for one dimension they show the increase in costs that occurs when this restriction alone is added to the scenarios (e.g. welfare costs increase by about $£ 20$ billion when nuclear energy is restricted), for several dimensions they show the cost increase caused by the interaction effect (on top of the effect of the individual dimensions; hence, welfare costs also increase by about $£ 40$ billion due to the interaction of $\mathrm{N}$ and $\mathrm{C}$, on top of the cost increases caused by $\mathrm{N}$ and $\mathrm{C}$ individually).

\footnotetext{
6 The design of a simple OLS-regression is used here with $W C=\alpha+\beta_{1} * N+\cdots+\beta_{n} * D+\gamma_{1} * N C+\cdots+\gamma_{n} * R D+\delta_{1} * B R D+\cdots+\delta_{n} * N R D+\theta_{1} * N B R D+\theta_{2} * N C B D ;$ with $W C=$ cumulated welfare costs; the independent variables represent the 5 dimensions and their interactions and have a value of 1 if the dimension is restricted and of 0 otherwise. In addition to the infeasible scenarios, the scenario CBRD is excluded as it is an outlier and would strongly bias the results. As the difference in technology dimensions is the only thing that is varied between the scenarios, the regression has an $\mathrm{R}^{2}$ value of one, i.e. the difference in technology dimensions and their interaction effects can perfectly describe the cost of the system
} 


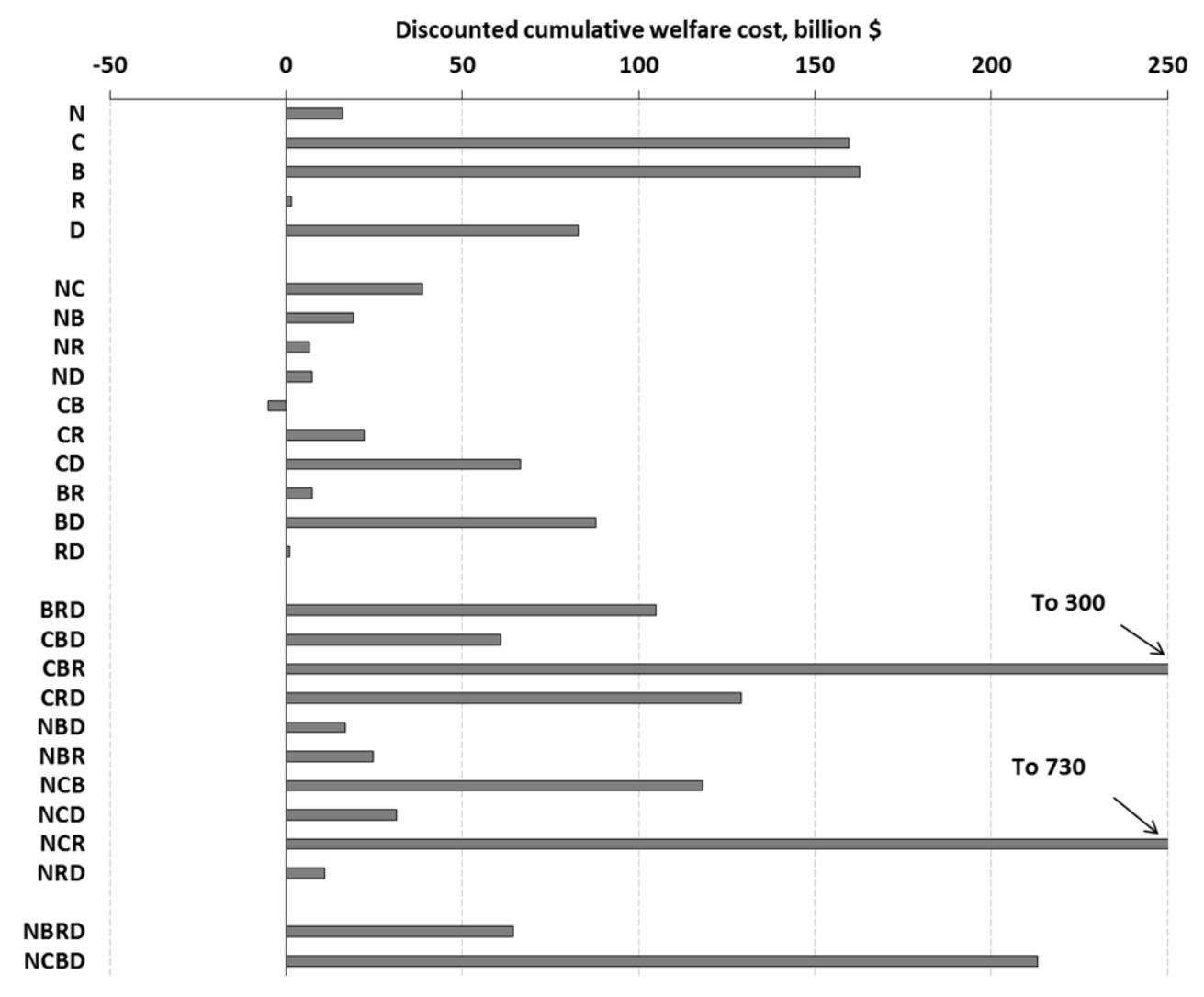

Figure 7: Coefficients of an OLS-regression on cumulated welfare costs

While the results confirm the general trends discussed above, it also highlights better the role of the interactions between the drivers. For example, scenarios CBD and CBR have comparable costs, but the regression analysis highlights how the welfare costs of the latter are especially driven by the interaction between the three drivers, whereas for the former, the impact of the individual drivers and the interactions between two driver elements explains most of the cost. It also shows that some dimensions only have a significant impact when combined with other restrictions. For example, restricting renewables alone, or in combination with only one other dimension, does not have a strong impact on welfare costs, whereas the interaction effects of dimension $\mathrm{R}$ with two other dimensions tend to be particularly high. Thus, restricting the development of renewable electricity generation will drive the costs of the UK energy transition significantly if other options, like nuclear energy or CCS, turn out to fail. This emphasizes again the importance of a balanced portfolio of low-carbon technology options.

\subsection{Insights on technology use}

\section{Complementarity and substitutability of technologies}

To gather further insights into the impact of uncertainty in the availability of low-carbon options on the long-term development of the UK energy system, we now look at technology complementarity and substitutability. To do this we assess which technologies are generally only used in combination with one another and which can easily substitute for each other. We calculate the correlation coefficients between the 5 technology dimensions (with a value of zero if the technology is restricted and of 1 if not) and the use of the most important fuels in 2050 (total or by sector). In Table 2 all coefficients with an absolute value over 0.5 are highlighted which are further explored in the following text. 
As already pointed out in Section 3.2, the use of natural gas is highly variable across the scenario matrix. A strong positive correlation of gas use, especially in hydrogen production, with CCS availability can be observed, highlighting the fact that significant gas use is only possible, in the long-term, if CCS is available. In contrast, less gas is needed if nuclear energy and renewable electricity options succeed in the long-term. Finally, gas demand is not strongly correlated with the resource potential of bioenergy. In the residential sector (and to a lesser extent in the industrial sector), there is a strong positive correlation between dimension $B$ and gas use, indicating that if higher amounts of bioenergy are available, there is less pressure to reduce gas use in heating in the end-use sectors.

Further investigation into the trend towards electrification reveals that total electricity demand in 2050 is only significantly correlated with biomass availability, i.e. if the bioenergy potential is strongly limited, greater electrification is required, especially in the industry and residential sector, while no such trend is observable when restricting the other dimensions. At the sector level, a more considerable uptake of electric heating and other devices takes place in the services and residential sectors if demandside change is constrained, balancing mostly the higher overall energy demand and the slower realization of conservation measures. In transport, electricity use is negatively correlated with CCS availability, highlighting that in the scenario analysis at hand, the long-term decarbonisation of the transport sector relies mainly on hydrogen, while a substantial uptake of electric vehicles only occurs if the option to produce hydrogen in CCS plants does not exist. The negative correlation between electricity use in hydrogen production and dimension $\mathrm{C}$ is of little relevance, given the generally low level of hydrogen produced from electricity.

Amongst the highest correlations between technology dimensions and fuel use in 2050 is the positive one between hydrogen use and CCS, emphasizing that CCS is essential to enable a strong contribution of hydrogen to the UK decarbonisation pathway. While in electricity generation a broader portfolio of low-carbon options is available, hydrogen generation strongly depends on CCS or bioenergy, where strong competition with other sectors needs to be taken into account.

Regarding the use of biomass, it has already been mentioned that the full potential is always exploited independent of the scenario assumptions. Accordingly, all correlations of total biomass use and the other technology dimensions are close to zero. In contrast, on the sector level, bioenergy demand is significantly correlated with CCS availability. Hence, a substantial amount of biomass is only used in electricity generation if the option of generating negative emissions through bio-CCS is given. In all scenarios without CCS, biomass in the end-use sectors is increased considerably, explaining the strong negative correlations, especially in the industry sector. However, this is not the case for the transport sectors, where biofuels never play a substantial long-term role. 
Table 2: Correlation coefficients between technology dimensions and fuel use in 2050 (coefficients $\geq 0.5$ are highlighted)

\begin{tabular}{|c|c|c|c|c|c|}
\hline Demand Dimension & $\mathbf{N}$ & C & B & $\mathbf{R}$ & D \\
\hline Gas, total & -0.50 & 0.73 & -0.12 & -0.50 & -0.05 \\
\hline Gas, ELC & -0.44 & 0.45 & -0.27 & -0.37 & -0.20 \\
\hline Gas, HYG & -0.27 & 0.66 & -0.29 & -0.26 & 0.25 \\
\hline Gas, residential & 0.00 & 0.24 & 0.61 & -0.08 & -0.11 \\
\hline Gas, services & -0.10 & 0.35 & -0.12 & -0.15 & 0.01 \\
\hline Gas, industry & -0.24 & 0.22 & 0.44 & -0.22 & 0.01 \\
\hline Gas, transport & 0.03 & -0.32 & 0.45 & -0.19 & -0.30 \\
\hline Electricity, total & 0.18 & -0.12 & -0.57 & 0.26 & -0.40 \\
\hline Electricity, residential & 0.11 & 0.06 & -0.51 & 0.24 & -0.50 \\
\hline Electricity, services & 0.12 & 0.41 & -0.36 & 0.15 & -0.59 \\
\hline Electricity, industry & 0.18 & 0.14 & -0.53 & 0.16 & -0.28 \\
\hline Electricity, transport & 0.08 & -0.90 & -0.27 & 0.22 & 0.13 \\
\hline Electricity, HYG & 0.31 & -0.70 & -0.13 & 0.25 & 0.15 \\
\hline Hydrogen, total & -0.27 & 0.66 & -0.28 & -0.26 & 0.24 \\
\hline Hydrogen, end use & -0.13 & 0.78 & -0.18 & -0.11 & 0.43 \\
\hline Renewables, total & -0.31 & -0.46 & -0.31 & 0.75 & -0.13 \\
\hline Renewables, ELC & -0.31 & -0.46 & -0.31 & 0.75 & -0.14 \\
\hline Biomass, total & -0.01 & -0.01 & 0.92 & -0.01 & 0.12 \\
\hline Biomass, ELC & -0.10 & 0.64 & 0.67 & -0.13 & 0.03 \\
\hline Biomass, end-use & 0.04 & -0.75 & 0.60 & 0.06 & 0.11 \\
\hline Biomass, residential & -0.07 & -0.61 & 0.48 & -0.05 & 0.31 \\
\hline Biomass, services & 0.03 & -0.76 & 0.46 & 0.02 & 0.11 \\
\hline Biomass, industry & 0.11 & -0.95 & 0.20 & 0.15 & 0.14 \\
\hline Biomass, transport & 0.03 & -0.21 & 0.95 & 0.03 & -0.03 \\
\hline CCS (sequestered emissions) & -0.31 & 0.91 & -0.02 & -0.28 & -0.04 \\
\hline
\end{tabular}

In addition to the significant correlations highlighted in Table 2, it is also interesting to examine some of the "non-correlations" which might be rather unexpected. First of all, the use of CCS is not correlated with biomass availability (correlation between dimension $\mathrm{B}$ and sequestered $\mathrm{CO}_{2}$ emissions). Thus, even if the possibility for bio-CCS is limited, the total use of CCS is not affected. Secondly, the insignificant correlation between the level of electrification and CCS availability indicates that while a limited bioenergy potential drives a higher electricity use, this is not the case for CCS. Lastly, there is a relatively low correlation between the available biomass resources and the use of bioenergy in industry showing that the industrial biomass demand is comparatively robust against changes in the biomass availability.

\section{Technology diffusion}

Another interesting dimension of future technology use are the diffusion rates of key decarbonisation technologies showing how ambitious some of the trajectories would have to be. Here, a special look is taken at some of the end-use sectors which have to deliver a significant contribution to emission abatement, especially in the case of multiple technology failure on the supply side.

In car transport (Figure 8), most scenarios feature high diffusion rates for hybrid vehicles (including plug-in hybrids) reaching a market share of around $40 \%$ (at the median) in 2030. In most scenarios, their market share starts to decline after 2040 (from up to 90\%), as more ambitious decarbonisation technologies diffuse more strongly. The share of electric cars remains below $20 \%$ in most scenarios, with some considerable exceptions of contributions of up to $30 \%$ in 2030 and $80 \%$ in 2050 (e.g. in scenario CBRD or NCBD). Hydrogen vehicles have, on average, a slightly higher market share then 
electric cars, but only reach a maximum of around 50\% in 2050 (e.g. in scenario NBRD). The very wide range across the technologies suggest that alternative transport futures can be imagined and these are likely to depend not only on the success of the transport technologies themselves, but also on the success of the technologies that are further up the supply chain (e.g. $\mathrm{H}_{2}$ production, $\mathrm{CCS}$, low carbon electricity).
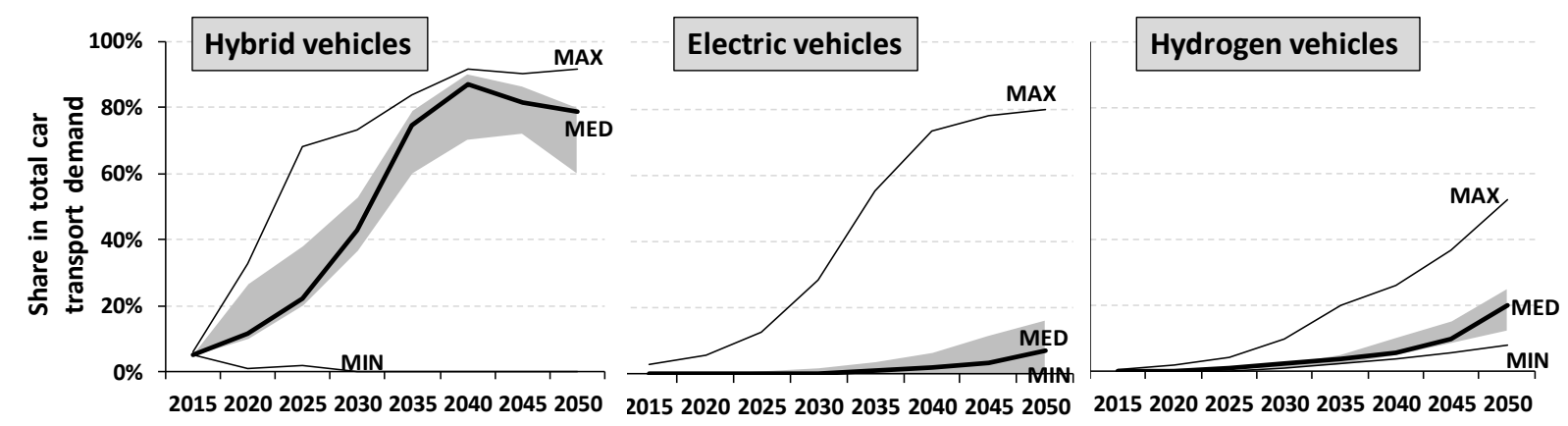

Figure 8: Diffusion rates in car transport across the scenario matrix (MED=median, grey area indicates the interquartile range)

In the residential sector (Figure 9), the abatement strategy relies strongly on heat pumps which exhibit highly ambitious diffusion rates reaching the maximally allowed share in the model of $60 \%$ already by 2040. This is mirrored by a gradual decline in the use of gas boilers, where the median share drops from over $80 \%$ in 2010 to $22 \%$ in 2050 . However, in some of the less constrained scenarios, gas boilers still contribute up to $58 \%$ to residential heating in 2050 . The share of hydrogen-based heating systems (both boilers and fuel cell micro-CHPs) in the residential sector remains negligible in most scenarios. Apart from that, moderate contributions of stand-alone electric heating systems and night storage heaters can be observed in most scenarios. The share of district heating in the residential sector remains below $10 \%$.

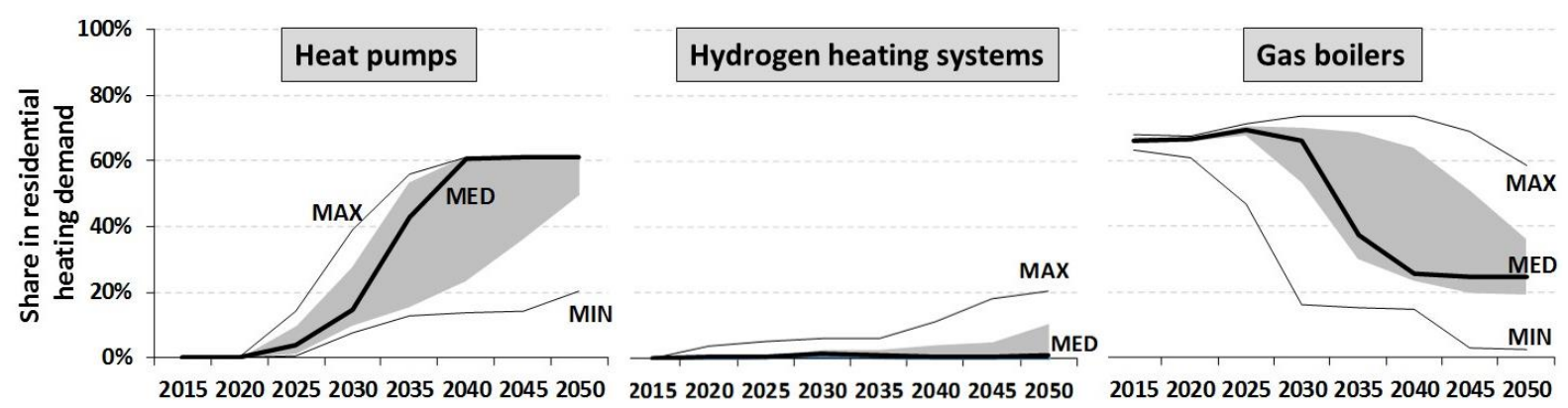

Figure 9: Diffusion rates in residential heating across the scenario matrix (MED=median, grey area indicates the interquartile range)

\section{Conclusions}

This analysis has shown how uncertainties in key low-carbon options, covering nuclear energy, CCS, bioenergy, renewable electricity technologies as well as demand-side change, can influence long-term decarbonisation pathways of the energy system and how multiple technology failures can interact to produce impacts that are more than additive. Using a technology-oriented, comprehensive energy system model allowed us to cover all the relevant repercussions within the energy system and to assess trade-offs between sectors and mitigation efforts. The approach of a global sensitivity analysis, applied here to a case study of the UK, can be easily transferred to other national or supranational settings.

By systematically varying the availability of one or several crucial mitigation options, critical insights can be gained on: 
- Variability across the uncertainty space. The analysis has identified an enormous range in the demand for natural gas across the scenario matrix, while other fuel uses are less variable. Also, the sector-wise contribution to emission abatement is highly sensitive to technology failure.

- Complementarity and substitutability of technologies. Some technology options only play a significant role in the decarbonisation pathway if other technologies are also available, seen, for example, in the strong dependency of hydrogen technologies on the prevalence of CCS. At the same time, some technologies can easily be substituted by others without entailing a significant cost increase. E.g., the analysis at hand indicates that in the UK energy system, replacing nuclear energy with other low-carbon electricity options would not cause a significant rise in electricity generation cost. From a risk perspective, the reliance on bio-CCS in some scenarios is interesting as it combines the unproved CCS with a resource with uncertain availability.

- Critical low-carbon options and hedging strategies. The use of some mitigation options is comparatively robust across the sensitivity analysis, e.g. the early decarbonisation of the electricity sector or considerable energy efficiency measures in the buildings and industry sector. The evaluation of cost parameters also reveals which options are most relevant to avoid a prohibitive cost burden in the case of multiple technology failure (especially CCS and renewable electricity options in this analysis). The sensitivity approach can also help to identify "failed" low-carbon technologies which never play a substantial role, such as ocean (wave and tidal) technologies in the present case. Moreover, the sensitivity analysis can reveal crucial hedging strategies in the presence of technology uncertainty that the reference case alone might not show, like a higher use of renewable sources or stronger focus on energy efficiency. For some of these options, such as efficiency measures in the buildings sector, policy measures will have to overcome significant investment barriers, but the technologies involved are a lot more mature and less risky than some of the options chosen in the reference case.

- Timing and path dependencies. While the analysis at hand has mostly focused on the endpoint of the model horizon, i.e. 2050, the sensitivity approach can also be used to assess the timing and pathways of the decarbonisation challenge. The scenario analysis clearly highlights that multiple technology uncertainty strongly increases the importance of early action in emission mitigation. Furthermore, analysing the diffusion rates of critical technologies indicates the ambition of low-carbon pathways under uncertainty.

In terms of future research, there are several possibilities to advance work sensitivity analysis presented here. First of all, the approach could be extended to account for further uncertainties. Here, integrative techniques, e.g. by including policy makers and other stakeholders or using expert elicitation (Usher \& Strachan, 2013), to identify the key uncertainties in the energy system should be further developed and tested. Secondly, while this analysis focuses on strong narratives and "in/out" options of technologies like CCS or nuclear, the economic and performance parameters of such technologies could also be varied over sensible ranges to explore robust ranges and tipping points in technology use. Thirdly, in order to examine the uncertainty space further, alternative uncertainty approaches should be applied to national energy systems analyses, e.g. stochastic methods or an assessment of the near-optimal solution space through MGA.

For policy makers, a deeper understanding of the main uncertainties in mitigation strategies as well as their interdependencies is crucial to formulate more robust decarbonisation strategies. The analysis has shown how multiple technology failures could put the achievement of long-term emission reduction targets in the UK at considerable risk. It has also shown how the failure or success, of a given technology can have wider impacts elsewhere in the energy system, thus complicating the management of a long- 
term energy transition. Further investigation is needed regarding the appropriate policy response to such an uncertain environment, i.e. should the government support a broad technology portfolio or move to "picking winners" early on? Sensitivity analysis, such as the one at hand, help to identify the key lowcarbon technologies and resources to which the low-carbon transition is particularly vulnerable and to raise the awareness in policy making to the extent of the uncertainty challenge.

\section{Acknowledgement}

This research was supported under the Whole Systems Energy Modelling Consortium (WholeSEM) Ref: EP/K039326/1. 


\section{References}

Anderson, B., Borgonovo, E., Galeotti, M., \& Roson, R. (2014). Uncertainty in Climate Change Modeling: Can Global Sensitivity Analysis Be of Help?. Risk Analysis, 34, 271-293. doi: http://dx. doi.org/10.1111/risa.12117

Anthoff, D. \& Tol, R. (2013). The uncertainty about the social cost of carbon: A decomposition analysis using fund. Climatic Change, 117(3), 515-530. doi: http://dx.doi.org/10.1007/s10584-013$\underline{0706-7}$

Beale, E. (1955). On minimizing a convex function subject to linear inequalities. J. R. Stat. Soc. B, 17, $173-184$.

BEIS (2016). Solar photovoltaics deployment. Department for Business, Energy \& Industrial Strategy, Retrieved from the GOV.UK website: https://www.gov.uk/government/statistics/solarphotovoltaics-deployment

Birmingham Policy Commission, 2012. The future of nuclear energy in the UK. University of Birmingham.

Branger, F., Giraudet, L., Guivarch, C., \& Quirion, P. (2015). Global sensitivity analysis of an energy-economy model of the residential building sector. Environmental Modelling \& Software, 70, 45-54. doi: http://dx.doi.org/10.1016/j.envsoft.2015.03.021

Brill, E.D., Jr., Flach, J.M., Hopkins, L.D., Ranjithan, S. (1990). MGA: A Decision Support System for Complex, Incompletely Defined Problems. IEEE Transactions on Systems, Man and Cybernetics, 20 (4), 745-757.

Calvin, K., Clarke, L., Krey, V., Blanford, G., Jiang, K., Kainuma, M., Kriegler, E., Luderer, G., \& Shukla, P.R. (2012). The role of Asia in mitigating climate change: Results from the Asia modeling exercise. Energy Economics, 34 (Supp 3), S251-S260, doi: http://dx.doi.org/10.1016/j.eneco.2012.09.003

Carbon Trust (2011). Accelerating marine energy, The potential for cost reduction - insights from the Carbon Trust Marine Energy Accelerator. London, UK.

Carrington, D. (2012, March 1). Local opposition to onshore windfarms has tripled, poll shows. The Guardian. Retrieved from http://www.theguardian.com

CCC (2008). Building a low-carbon economy - the UK's contribution to tackling climate change. London: Committee on Climate Change.

CCC (2011). Time preference, costs of capital and hidden costs: a Committee on Climate Change Note. Retrieved from the CCC website: http://archive.theccc.org.uk/aws/Time\%20prefernce,\%20costs \%20of\%20capital\%20and\%20hiddencosts.pdf

CCC (2011a). Bioenergy Review. London: Committee on Climate Change.

CCC (2011b). The Renewable Energy Review. London: Committee on Climate Change.

CCC (2013). Fourth Carbon Budget Review - part 2, The cost-effective path to the 2050 target. London: Committee on Climate Change.

Chang, S.-Y., Brill Jr, E.D., \& Hopkins, L.D. (1982). Efficient random generation of feasible alternatives: a land use example. Journal of Regional Science, 22 (3), 303-314. 
Daly, H. E., Scott, K., Strachan, N., \& Barrett, J. (2015). Indirect $\mathrm{CO}_{2}$ Emission Implications of Energy System Pathways: Linking IO and TIMES Models for the UK. Environmental Science \& Technology, 49(17), 10701-10709. doi: 10.1021/acs.est.5b01020

DeCarolis, J. (2011). Using modeling to generate alternatives (MGA) to expand our thinking on energy futures. Energy Economics, 33(2), 145-152, doi: 10.1016/j.eneco.2010.05.002

DECC (2011a). The Carbon Plan: Delivering our low carbon future. London: Department of Energy and Climate Change.

DECC (2011b). UK Renewable Energy Roadmap. London: Department of Energy and Climate Change.

DECC (2012a). DECC Dynamic Dispatch Model (DDM). London: Department of Energy and Climate Change.

DECC (2012b). CCS Roadmap - Supporting deployment of Carbon Capture and Storage in the UK. London: Department of Energy and Climate Change.

DECC (2013). Electricity Generation Costs (December 2013). London: Department of Energy and Climate Change.

DECC (2014a, February 19). DECC and industry sets out plan to stay "world leader" in offshore wind and boost economy. Retrieved from https://www.gov.uk/government/organisations/department-of-energy-climate-change

DECC (2014b). Updated energy and emissions projections 2014. Retrieved from the GOV.UK website: https://www.gov.uk/government/uploads/system/uploads/attachment_data/file/368021/ Updated energy and emissions projections2014.pdf

DECC (2014c). Fossil fuel price projections: 2014. Retrieved from the GOV.UK website: https://www.gov.uk/government/publications/fossil-fuel-price-projections-2014

DECC (2015, December 17). Changes to renewables subsidies (press release). Retrieved from https://www.gov.uk/government/organisations/department-of-energy-climate-change

Dodds, P. E., \& McDowall, W. (2014). Methodologies for representing the road transport sector in energy system models. International Journal of Hydrogen Energy, 39(5), 2345-2358. doi: 10.1016/j.ijhydene.2013.11.021

DTI (2007). Energy White Paper: Meeting the Energy Challenge. London: Department of Trade and Industry.

Edenhofer, O., Lessmann, K., Kemfert, C., Grubb, M., \& Kohler, J. (2006). Induced Technological Change: Exploring its Implications for the Economics of Atmospheric Stabilization: Synthesis Report from the Innovation Modeling Comparison Project. The Energy Journal, Endogenous Technological Change, Special Issue \#1, 57-108. doi: 10.5547/ISSN0195-6574-EJ-VolSI2006NoSI1-3

Ekins, P., Anandarajah, G., \& Strachan, N. (2011). Towards a low-carbon economy: scenarios and policies for the UK. Climate Policy, 11(2), 865-882. doi: 10.3763/cpol.2010.0126

Enviros (2005). The Cost of Supplying Renewable Energy. A report for DTI. London: Enviros Consulting. 
European Climate Foundation (2010). Roadmap 2050: A practical guide to a prosperous, low-carbon Europe. Retrieved from the roadmap2050 website: http://www.roadmap2050.eu/attachments/files/ Volume1 fullreport PressPack.pdf

Energiewirtschaftliches Institut an der Universität zu Köln (EWI), Gesellschaft für Wirtschaftliche Strukturforschung (GWS), Prognos AG (2010). Energieszenarien für ein Energiekonzept der Bundesregierung. Report for Federal Ministry of Economy and Technology. Basel, Köln, Osnabrück.

European Commission (EC) (2009). Directive 2009/28/EC of the European Parliament and of the Council of 23 April 2009 on the promotion of the use of energy from renewable sources and amending and subsequently repealing Directives 2001/77/EC and 2003/30/EC. Brussels: European Commission (EC).

Fais, B., Sabio, N., \& Strachan, N. (2016a). The critical role of the industrial sector in reaching longterm emission reduction, energy efficiency and renewable targets. Applied Energy, 162, 699-712. doi: 10.1016/j.apenergy.2015.10.112

Fais, B., Daly, H. E., \& Dodds, P. E. (2016b). UK TIMES Model Documentation, version 1.0. London. UCL Energy Institute. (Forthcoming)

Grübler, A., Nakićenović, N., Victor, D. (1999). Dynamics of energy technologies and global change, Energy Policy, 27(5), 247-280. doi:10.1016/S0301-4215(98)00067-6.

Haggett, C. (2011). Understanding public responses to offshore wind power. Energy Policy, Special Section on Offshore wind power planning, economics and environment 39, 503-510. doi:10.1016/j.enpol.2010.10.014

Heptonstall, P., Gross, R., Greenacre, P., Cockerill, T., (2012). The cost of offshore wind: Understand-ing the past and projecting the future. Energy Policy, Modeling Transport (Energy) Demand and Policies 41, 815-821. doi:10.1016/j.enpol.2011.11.050

Higgins, P., Foley, A., 2014. The evolution of offshore wind power in the United Kingdom. Renewable and Sustainable Energy Reviews 37, 599-612. doi:10.1016/j.rser.2014.05.058

HM Government (2008). Climate Change Act 2008. London: HM Government.

HM Government (2015, November 25). HM Government Statement to Markets Regarding Carbon Capture and Storage Competition. London: HM Government.

HM Treasury (2011). The Green Book. London: HM Treasury.

Höök, M., Li, J., Johansson, K., Snowden, S. (2012). Growth Rates of Global Energy Systems and Future Outlooks. Natural Resources Research, 21(1), 23-41. doi:10.1007/s11053-011-9162-0

International Energy Agency (IEA) (2011). Technology Roadmap - Biofuels for Transport. Paris: Organisation for Economic Co-operation and Development (OECD) / International Energy Agency (IEA).

International Energy Agency (IEA) (2012). Technology Roadmap - Bioenergy for Heat and Power. Paris: Organisation for Economic Co-operation and Development (OECD) / International Energy Agency (IEA).

International Energy Agency (IEA) (2015a). World Energy Outlook 2015. Paris: Organisation for Economic Co-operation and Development (OECD) / International Energy Agency (IEA). 
International Energy Agency (IEA) (2015b). Energy Technology Perspectives 2015 - Mobilising Innovation to Accelerate Climate Action. Paris: Organisation for Economic Co-operation and Development (OECD) / International Energy Agency (IEA).

IPCC (2014). Intergovernmental Panel on Climate Change Fifth Assessment Report (AR5). Geneva, Switzerland: Intergovernmental Panel on Climate Change.

Jaffe, A. B., \& Stavins, R. N. (1994). The energy-efficiency gap - What does it mean? Energy Policy, 22(10), 804-810. doi: 10.1016/0301-4215(94)90138-4

Kannan, R., Strachan, N., Pye, S. Anandarajah, G., \& Balta-Ozkan, N. (2007). UK MARKAL Model Documentation. Retrieved from the UCL Energy Institute Models website: www.ucl.ac.uk/energymodels/models/uk-markal

Kanudia, A., \& Loulou, R. (1998). Robust responses to climate change via stochastic MARKAL: The case of Québec. European Journal of Operational Research, 106(1), 15-30, doi: 10.1016/S03772217(98)00356-7

Keppo, I., \& van der Zwaan, B. (2012). The Impact of Uncertainty in Climate Targets and $\mathrm{CO}_{2}$ Storage Availability on Long-Term Emissions Abatement. Environmental Modeling and Assessment, 17(1-2), 177-191, doi: 10.1007/s10666-011-9283-1

Knopf, B., Chen, Y.-HH., De Cian, E., Förster, H., Kanudia, A., Karkatsouli, I., \& Keppo, I. (2013). Beyond 2020 - Strategies and costs for transforming the European energy system. Climate Change Economics , 4 (Suppl.). doi: 10.1142/S2010007813400010

Krey, V., Martinsen, D., \& Wagner, H. (2007). Effects of stochastic energy prices on long-term energy-economic scenarios. Energy, 32(12), 2340-2349. doi: 10.1016/j.energy.2007.05.013

Kriegler, E., Weyant, J.P., Blanford, G; Krey, V., Clarke, L., Edmonds, J., .., van Vuuren, D. (2014): The role of technology for achieving climate policy objectives: overview of the EMF 27 study on global technology and climate policy strategies. Climatic Change, 123(3), 353-367. doi: 10.1007/s10584-013-0953-7

Kriegler, E., Riahi, K., Bauer, N., Schwanitz, V.J., Petermann, N., Bosetti, V., .., Edenhofer, O. (2015). Making or breaking climate targets: The AMPERE study on staged accession scenarios for climate policy. Technological Forecasting and Social Change, 90(A), 24-44. doi: 10.1016/j.techfore.2013.09.021

Immerzeel, D. J., Verweij, P. A., van der Hilst, F. and Faaij, A. P. C. (2014). Biodiversity impacts of bioenergy crop production: a state-of-the-art review. GCB Bioenergy, 6, 183-209. doi: $10.1111 /$ gcbb.12067

Labriet, M., Kanudia, A., \& Loulou, R. (2012). Climate mitigation under an uncertain technology future: A TIAM-World analysis. Energy Economics, 34(S3), S366-S377. doi: 10.1016/j.eneco.2012.02.016

Loulou, R., \& Lehtilä, A. (2012). Stochastic Programming and Tradeoff Analysis in TIMES. Version 3.3 User Note. Retrieved from the Energy Technology Systems Analysis Program (ETSAP) website: http://www.iea-etsap.org/web/Documentation.asp

Loulou, R., Remme, U., Lehtilä, A., Kanudia, A., \& Goldstein, G. (2005). Documentation for the TIMES model. Retrieved from the Energy Technology Systems Analysis Program (ETSAP) website: http://www.iea-etsap.org/web/Documentation.asp

MacKay, D. (2009). Sustainable Energy - without the hot air. Cambridge, England: UIT. 
McKinsey (2007). Reducing U.S. Greenhouse Gas Emissions: How Much at What Cost? McKinsey \& Company.

McLaren Loring, J. (2007). Wind energy planning in England, Wales and Denmark: Factors influencing project success. Energy Policy 35, 2648-2660. doi:10.1016/j.enpol.2006.10.008

Mott MacDonald (2010). UK Electricity Generation Costs Update. Brighton.

Mundaca, L., Neij, L., Worrell, E., \& McNeil, M., 2010. Evaluating Energy Efficiency Policies with Energy-Economy Models. Annual Review of Environment and Resources, 35(1), 305-344. doi: 10.1146/annurev-environ-052810-164840

National Grid (2012). Solar PV (electricity systems) and the National Grid: a briefing note for DECC. Retrieved from https://www.gov.uk/government/organisations/department-of-energy-climatechange

ONS (2013). National Population Projections, 2012-based projections. Newport: Office for National Statistics. Retrieved from http://www.ons.gov.uk/

Perveen, R., Kishor, N., Mohanty, S.R., 2014. Off-shore wind farm development: Present status and challenges. Renewable and Sustainable Energy Reviews, 29, 780-792. doi: 10.1016/j.rser.2013.08.108

Pfenninger, S., \& Keirstead, J. (2015). Renewables, nuclear, or fossil fuels? Scenarios for Great Britain's power system considering costs, emissions and energy security. Applied Energy, 152, 8393. doi: 10.1016/j.apenergy.2015.04.102

Poortinga, W., Pidgeon, N. F., Capstick, S., \& Aoyagi, M. (2013). Public Attitudes to Nuclear Power and Climate Change in Britain Two Years after the Fukushima Accident. Working Paper UKERC/WP/ES/2013/006, UK Energy Research Centre.

Pye, S., Sabio, N., \& Strachan, N. (2015). An integrated systematic analysis of uncertainties in UK energy transition pathways. Energy Policy, 87, 673-684. doi: 10.1016/j.enpol.2014.12.031

Pye, S., Usher, W., \& Strachan, N. (2014). The uncertain but critical role of demand reduction in meeting long-term energy decarbonisation targets. Energy Policy, 73, 575-586. doi: 10.1016/j.enpol.2014.05.025

Raconteur (2014, November 11). UK Wind \& Marine Business Barometer 2014. Retrieved from http://raconteur.net/

Raskin, P., Monks, F., Ribeiro, T., van Vuuren, D., \& Zurek, M. (2005). Global Scenarios in Historical Perspective. In Carpenter, S. (ed.), Pingali , P. (ed.), Bennett, E. (ed.), \& Zurek, M. (ed.), Ecosystems and Human Well-Being: Scenarios - Findings of the Scenarios Working Group Millennium Ecosystem Assessment Series (pp. 35-44). Washington, DC: Island Press.

renewableUK (2015a). Wind Energy in the UK - State of the Industry Report 2015. London: RenewableUK.

renewableUK (2015b). Offshore Wind Project Timelines. Retrieved from http://www.renewableuk.com/

Saltelli, A., Annoni, P., \& D'Hombres, B. (2010). How to avoid a perfunctory sensitivity analysis. Procedia - Social and Behavioral Sciences, 2(6), 7592-7594. doi: 10.1016/j.sbspro.2010.05.133 
Seljom, P., \& Tomasgard, A. (2015). Short-term uncertainty in long-term energy system models - A case study of wind power in Denmark. Energy Economics, 49, 157-167. doi:

10.1016/j.eneco.2015.02.004

Strachan, N., \& Usher, W. (2010). UK MARKAL Modelling - Examining Decarbonisation Pathways in the 2020s on the Way to Meeting the 2050 Emissions Target (Final Report for the Committee on Climate Change). Retrieved from the UCL Energy Institute website:

http://www.ucl.ac.uk/energy-models/models/uk-markal/ccc-fourth-carbon-budget-final-report-ukmarkal-updates

Strachan, Neil, \&Will Usher. "Failure to Achieve Stringent Carbon Reduction Targets in a SecondBest Policy World." Climatic Change 113, no. 2 (October 11, 2011): 121-139. doi:10.1007/s10584-011-0267-6.

Strbac, G., Aunedi, M., Pudjianto, D., Teng, F., Djapic, P., Druce, R., Carmel, A., Borkowski, K. (2015). Value of Flexibility in a Decarbonised Grid and System Externalities of Low-Carbon Generation Technologies. Report for the Committee on Climate Change. Imperial College London $\&$ NERA Economic Consulting.

Syri, S., Lehtilä, A., Ekholm, T., Savolainen, I., Holttinen, H., Peltola, E. (2008). Global energy and emissions scenarios for effective climate change mitigation-Deterministic and stochastic scenarios with the TIAM model. International Journal of Greenhouse Gas Control, 2(2), 274-285, doi: 10.1016/j.ijggc.2008.01.001

Tavoni, M., Kriegler, E., Aboumaboub, T., Calvin, K.V., De Maeure, G., Kober, T., ..., McCollum, D. (2013). The distribution of the major economies' effort in the Durban platform scenarios. Climate Change Economics, 4(4). doi: 10.1142/S2010007813400095

Trutnevyte, E. (2013). EXPANSE methodology for evaluating the economic potential of renewable energy from an energy mix perspective. Applied Energy, 111, 593-601, doi:

10.1016/j.apenergy.2013.04.083

Trutnevyte, E., Guivarch, C., Lempert, R., \& Strachan, N. (2016). Reinvigorating the scenario technique to expand uncertainty consideration. Climatic Change (forthcoming).

Tyndall Centre for Climate Change Research (2013). A Review of Research Relevant to New Build Nuclear Power Plants in the UK. University of Manchester.

Usher, W. (2016). The Value of Learning about Critical Energy System Uncertainties. Doctoral thesis, University College London. Retrieved from http://discovery.ucl.ac.uk/1504608/

Usher, W., \& Strachan, N. (2012). Critical mid-term uncertainties in long-term decarbonisation pathways. Energy Policy, 41, 433-444. doi: 10.1016/j.enpol.2011.11.004

Usher, W., \& Strachan, N. (2013). An expert elicitation of climate, energy and economic uncertainties. Energy Policy, 61, 811-821. doi: 10.1016/j.enpol.2013.06.110

van Vuuren, D., de Vries, B., Beusen, A., \& Heuberger, P. (2008). Conditional probabilistic estimates of 21st century greenhouse gas emissions based on the storylines of the IPCC-SRES scenarios. Global Environmental Change, 18(4), 635-654, doi: 10.1016/j.gloenvcha.2008.06.001

Voll, P., Jennings, M., Hennen, M., Shah, N., Bardow, A. (2015). The optimum is not enough: A near-optimal solution paradigm for energy systems synthesis. Energy, 82, 446-456. doi: 10.1016/j.energy.2015.01.055 
Yang, Ch., Yeh, S., Zakerinia, S., Ramea, K., McCollum, D. (2015). Achieving California's 80\% greenhouse gas reduction target in 2050: Technology, policy and scenario analysis using CATIMES energy economic systems model. Energy Policy, 77, 118-130. doi:

10.1016/j.enpol.2014.12.006

Wainwright, H., Finsterle, S., Jung, Y., Zhou, Q., \& Birkholzer, J. (2014). Making sense of global sensitivity analyses. Computers \& Geosciences, 65, 84-94. doi: 10.1016/j.cageo.2013.06.006

Watson, J., Kern, F., Gross, M., Gross, R., Heptonstall, P., Jones, F., ... Arapostathis, S. (2012). Carbon Capture and Storage: Realising the Potential? (Project Report). London: UK Energy Research Centre.

Weyant, J.P. (1993). Costs of Reducing Global Carbon Emissions. Journal of Economic Perspectives, 7(4), 27-46.

Weyant, J.P., Kriegler, E. (2014). Preface and introduction to EMF 27. Climatic Change, 123(3), 345352. doi: 10.1007/s10584-014-1102-7

Wilson, C., Grübler, A., Bauer, N. Krey, V., Riahi, K. (2013). Future capacity growth of energy technologies: are scenarios consistent with historical evidence? Climatic Change, 118(2), 381395. doi: 10.1007/s10584-012-0618-y 


\section{Annex}

Table A-1: Background on modelling techniques to represent uncertainty in energy-economic models

\begin{tabular}{|c|c|}
\hline $\begin{array}{l}\text { Sensitivity } \\
\text { analysis }\end{array}$ & $\begin{array}{l}\text { The most commonly used method to evaluate uncertainty in deterministic models } \\
\text { analysing the variability of the model output as a function of changing input } \\
\text { parameters. In most cases, local or one-at-a-time sensitivity analyses are conducted, } \\
\text { which, however, do not capture the interactions between input parameters (Saltelli } \\
\text { et al., 2010). This has led to a couple of studies using global sensitivity techniques, } \\
\text { which vary several uncertain input parameters at a time to explore the interaction } \\
\text { effects, in some cases through probabilistic and Monte Carlo methods (Wainwright } \\
\text { et al., 2014). Recent studies in energy systems research include van Vuuren et al. } \\
\text { (2008), Anthoff \& Tol (2013), Anderson et al. (2014), Branger et al. (2015), Pye et al. } \\
\text { (2015) and Usher (2016) }\end{array}$ \\
\hline $\begin{array}{l}\text { Stochastic } \\
\text { modelling }\end{array}$ & $\begin{array}{l}\text { Stochastic modelling moves away from the deterministic approach still applied in } \\
\text { sensitivity analysis and deals explicitly with optimal decision-making under } \\
\text { uncertainty by applying probabilities to unknown future parameters (Beale, 1955; } \\
\text { Loulou \& Lehtila, 2012). This has the advantage of accounting for the cost of } \\
\text { uncertainty, relaxing the assumption of perfect foresight and analysing hedging } \\
\text { strategies. Stochastic programming has been applied to a large variety of input } \\
\text { assumptions in energy systems modelling, like energy prices (Krey et al., 2007), } \\
\text { resource availability (Usher \& Strachan, 2012), technology parameters (Labriet et } \\
\text { al., 2012), climate sensitivity (Syri et al., 2008), the stringency of mitigation targets } \\
\text { (Kanudia \& Loulou, 1998) and the stochasticity of intermittent renewable resources } \\
\text { (Seljom \& Tomasgarda, 2015). }\end{array}$ \\
\hline $\begin{array}{l}\text { Modelling to } \\
\text { Generate } \\
\text { Alternatives } \\
\text { (MGA) }\end{array}$ & $\begin{array}{l}\text { An optimization technique that explores the near-optimal solution space for feasible } \\
\text { solutions that are maximally different from the optimal pathway (Brill et al., 1990). } \\
\text { This technique takes into account that the single solution of an optimization } \\
\text { approach never reflects the full uncertainty and practical constraints of the real- } \\
\text { world system and allows to assess both common features and significant differences } \\
\text { in the near-optimal solution space. Originally mostly applied in land and water } \\
\text { management (e.g. Chang et al., (1982)), first applications in long-term energy } \\
\text { optimization models can be found (DeCarolis, 2011; Trutnevyte, 2013; Voll et al. } \\
\text { 2015). }\end{array}$ \\
\hline $\begin{array}{l}\text { Multi-model } \\
\text { comparisons }\end{array}$ & $\begin{array}{l}\text { Multi-model comparisons are increasingly applied to examine both parameter and } \\
\text { structural (or model) uncertainty. Such studies involve running a predefined set of } \\
\text { scenarios in several modelling frameworks (mostly Integrated Assessment Models) } \\
\text { with diverse model structures and input parameters (with different degrees of } \\
\text { harmonization) (Edenhofer et al., 2006). The aim is to arrive at a range of plausible } \\
\text { mitigation pathways, to explore the impact of different model structures and to } \\
\text { assess the relevance of different input parameters. Multi-model comparison studies } \\
\text { have been pioneered by the Energy Modelling Forum (EMF) (Weyant, 1993; Knopf } \\
\text { et al., 2013; Kriegler et al., 2014), but have since also been carried out through } \\
\text { projects like AMPERE (Kriegler et al., 2015), LIMITS (Tavoni et al., 2013) and the } \\
\text { Asian Modeling Exercise (AME) (Calvin et al., 2012). A recent review can be found in } \\
\text { Weyant \& Kriegler (2014). }\end{array}$ \\
\hline
\end{tabular}


Table A-2: $\quad$ Investment cost assumptions for electricity generation technologies in UKTM (selection) [£/kW]

\begin{tabular}{|l|c|c|c|c|}
\hline & $\mathbf{2 0 2 0}$ & $\mathbf{2 0 3 0}$ & $\mathbf{2 0 4 0}$ & $\mathbf{2 0 5 0}$ \\
\hline Coal CCS & 2707 & 2707 & 2700 & 2700 \\
\hline Gas, OCGT & 287 & 287 & 286 & 286 \\
\hline Gas, CCGT & 561 & 561 & 561 & 561 \\
\hline Gas, CCGT CCS & 1185 & 1185 & 1179 & 1179 \\
\hline Nuclear & 4019 & 4019 & 3973 & 3973 \\
\hline Biomass combustion, large & 2324 & 2280 & 2275 & 2275 \\
\hline Biomass combustion, CCS & 3626 & 3626 & 3610 & 3610 \\
\hline Biogas, gas engine & 3885 & 3791 & 3780 & 3780 \\
\hline Wind, onshore & & & & \\
\hline Central case & 1477 & 1408 & 1398 & 1398 \\
\hline Restricted & 1477 & 1408 & 1398 & 1398 \\
\hline Wind, offshore & & & & \\
\hline Central case & 2229 & 1982 & 1764 & 1764 \\
\hline Restricted & 2472 & 2472 & 2472 & 2472 \\
\hline Solar farms & & & & \\
\hline Central case & 786 & 523 & 523 & 523 \\
\hline Restricted & 980 & 980 & 980 & 980 \\
\hline Solar, rooftop & & & & \\
\hline Central case & 1499 & 1190 & 1190 & 1190 \\
\hline Restricted & 1713 & 1713 & 1713 & 1713 \\
\hline
\end{tabular}

Table A-3: Assumptions under technology dimension renewable electricity $(R)$

\begin{tabular}{|c|c|c|}
\hline Source & Central Case & Sensitivity renewable electricity $(R)$ \\
\hline Onshore wind & $\begin{array}{l}\text { Potential: } 36.9 \mathrm{GW} \text { (Enviros, 2005) } \\
\text { Capital cost: Current DDM assumptions (DECC, } \\
2012 \mathrm{a}),-12 \% \text { between } 2010 \text { and } 2050 \text { (to } \\
1400 \mathrm{f} / \mathrm{kW} \text { ) }\end{array}$ & $\begin{array}{l}\text { Potential: } 15 \text { GW (Enviros, 2005) } \\
\text { Capital cost: same as in central }\end{array}$ \\
\hline Offshore wind & $\begin{array}{l}\text { Potential: } 327 \text { GW (Enviros, 2005); limited to } \\
49 \text { GW until } 2030 \text { (amount leased so far) } \\
\text { Capital cost: }-35 \% \text { between } 2010 \text { and } 2050 \text { (to } \\
1800 \text { f/kW) (Mott McDonald, 2010) }\end{array}$ & $\begin{array}{l}\text { Potential: } 16 \mathrm{GW} \text { (current total with planning } \\
\text { permission (renewableUK, 2015b) } \\
\text { Capital cost: no learning effects after 2015, costs } \\
\text { at } 2500 \mathrm{f} / \mathrm{kW} \text { in } 2050\end{array}$ \\
\hline Solar PV & $\begin{array}{l}\text { Potential: } 45 \text { GW (current DDM assumptions) } \\
\text { Capital cost: Current DDM assumptions, }-47 \% \\
\text { / -34\% between } 2010 \text { and } 2050 \text { (to } 520 / 1190 \\
\text { f/kW (farm / rooftop)) }\end{array}$ & $\begin{array}{l}\text { Potential: } 20 \mathrm{GW} \text { (National Grid, 2012) } \\
\text { Capital cost: no learning effects after 2015, costs } \\
\text { at } 980 \text { / } 1700 \mathrm{f} / \mathrm{kW} \text { (farm / rooftop) }\end{array}$ \\
\hline Marine & $\begin{array}{l}\text { Potential: } 27 \text { GW (Carbon Trust, 2011) } \\
\text { Capital cost: Current DDM assumptions, with } \\
7500 \mathrm{f} / \mathrm{kW} \text { (wave) \& } 3900 \mathrm{f} / \mathrm{kW} \text { (tidal stream) } \\
\text { in } 2050\end{array}$ & Not available \\
\hline Geothermal & $\begin{array}{l}\text { Potential: } 2 \text { GW (current DDM assumptions) } \\
\text { Capital cost: Current DDM assumptions, with } \\
3900 \mathrm{f} / \mathrm{kW} \text { in } 2050\end{array}$ & Not available \\
\hline
\end{tabular}


Table A-4: Development of the carbon price $\left[£ / t \mathrm{CO}_{2} \mathrm{eq}\right]$ in the 28 scenarios

\begin{tabular}{|c|c|c|c|c|c|}
\hline & 2020 & 2030 & 2040 & 2050 & $\begin{array}{l}\text { Increase in } 2050 \\
\text { compared to REF }\end{array}$ \\
\hline REF & 27 & 128 & 180 & 244 & \\
\hline $\mathbf{N}$ & 24 & 139 & 196 & 266 & $9 \%$ \\
\hline C & 26 & 320 & 450 & 612 & $150 \%$ \\
\hline B & 27 & 273 & 384 & 522 & $114 \%$ \\
\hline $\mathbf{R}$ & 25 & 128 & 180 & 244 & $0 \%$ \\
\hline D & 25 & 190 & 267 & 363 & $49 \%$ \\
\hline NC & 26 & 383 & 540 & 734 & $200 \%$ \\
\hline NB & 25 & 295 & 415 & 564 & $131 \%$ \\
\hline NR & 24 & 144 & 202 & 275 & $13 \%$ \\
\hline ND & 24 & 204 & 287 & 390 & $60 \%$ \\
\hline CB & 25 & 453 & 639 & 868 & $255 \%$ \\
\hline CR & 26 & 393 & 554 & 752 & $208 \%$ \\
\hline CD & 25 & 400 & 564 & 767 & $214 \%$ \\
\hline BR & 26 & 287 & 405 & 550 & $125 \%$ \\
\hline BD & 24 & 380 & 535 & 727 & $198 \%$ \\
\hline RD & 27 & 192 & 271 & 368 & $50 \%$ \\
\hline NCB & 25 & 890 & 1255 & 1705 & $598 \%$ \\
\hline NCR & 31 & 3689 & 5200 & 7063 & $2791 \%$ \\
\hline NCD & 26 & 621 & 875 & 1189 & $387 \%$ \\
\hline NBR & 24 & 356 & 502 & 681 & $179 \%$ \\
\hline NBD & 25 & 438 & 618 & 840 & $244 \%$ \\
\hline NRD & 24 & 213 & 301 & 408 & $67 \%$ \\
\hline CBR & 35 & 1819 & 2565 & 3484 & $1326 \%$ \\
\hline CBD & 24 & 886 & 1249 & 1696 & $594 \%$ \\
\hline CRD & 28 & 816 & 1150 & 1562 & $539 \%$ \\
\hline BRD & 24 & 455 & 641 & 871 & $257 \%$ \\
\hline NCBD & 25 & 1637 & 2307 & 3134 & $1183 \%$ \\
\hline NBRD & 25 & 775 & 1092 & 1484 & $507 \%$ \\
\hline CBRD & 33 & 19668 & 27724 & 37661 & $15313 \%$ \\
\hline
\end{tabular}

